\title{
A Review on Mesenchymal Stem Cells for Treatment of Retinal Diseases
}

\author{
Sanjucta Adak $^{1} \cdot$ Damaris Magdalene $^{2}$ (D) $\cdot$ Saurabh Deshmukh $^{2}$ (D) $\cdot$ Dipankar Das $^{3}$ (D) $\cdot$ Bithiah Grace Jaganathan $^{1}$ (D)
}

Accepted: 16 November 2020 / Published online: 6 January 2021

(C) Springer Science+Business Media, LLC, part of Springer Nature 2021

\begin{abstract}
Mesenchymal Stem Cells (MSCs) have been studied extensively for the treatment of several retinal diseases. The therapeutic potential of MSCs lies in its ability to differentiate into multiple lineages and secretome enriched with immunomodulatory, antiangiogenic and neurotrophic factors. Several studies have reported the role of MSCs in repair and regeneration of the damaged retina where the secreted factors from MSCs prevent retinal degeneration, improve retinal morphology and function. MSCs also donate mitochondria to rescue the function of retinal cells and exosomes secreted by MSCs were found to have anti-apoptotic and anti-inflammatory effects. Based on several promising results obtained from the preclinical studies, several clinical trials were initiated to explore the potential advantages of MSCs for the treatment of retinal diseases. This review summarizes the various properties of MSCs that help to repair and restore the damaged retinal cells and its potential for the treatment of retinal degenerative diseases.
\end{abstract}

Key words Retinal regeneration $\cdot$ cell replacement therapy $\cdot$ exosomes $\cdot$ mitochondrial transfer $\cdot$ anti-inflammatory molecules

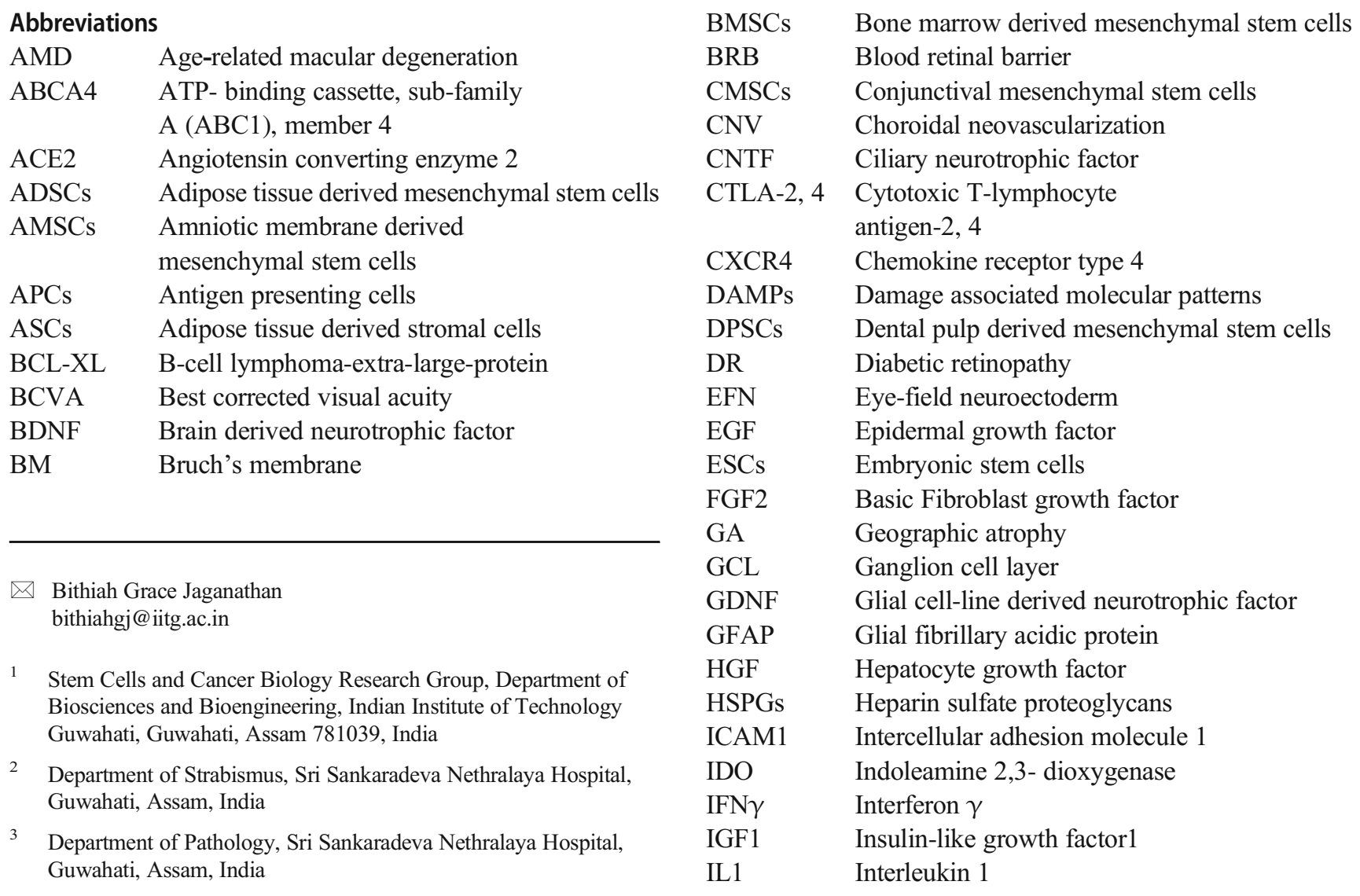




\begin{tabular}{|c|c|}
\hline IL6 & Interleukin 6 \\
\hline IL8 & Interleukin 8 \\
\hline IL10 & Interleukin 10 \\
\hline IL17 & Interleukin 17 \\
\hline IL22 & Interleukin 22 \\
\hline $\operatorname{IL} 1 \beta$ & Interleukin $1 \beta$ \\
\hline ILM & Inner limiting membrane \\
\hline INL & Inner nuclear layer \\
\hline IOP & Intraocular pressure \\
\hline iPSCs & Induced pluripotent stem cells \\
\hline MCP1 & Monocyte chemoattractant protein 1 \\
\hline MERTK & Mer receptor tyrosine kinase \\
\hline MMP-9 & Matrix metalloproteinase-9 \\
\hline MSCs & Mesenchymal stem cells \\
\hline NSCs & Neural stem cells \\
\hline NGF & Nerve growth factor \\
\hline NMDA & N-methyl-D-aspartate \\
\hline NO & Nitric oxide \\
\hline NPDR & Non-proliferative stage of diabetic retinopath \\
\hline NT-3,4/5 & Neurotrophin-3, 4/5 \\
\hline NTFs & Neurotrophic factors \\
\hline ONL & Outer nuclear layer \\
\hline PAMPs & Pathogen associated molecular patterns \\
\hline PAX6 & Paired box 6 protein \\
\hline PDR & Proliferative stage of diabetic retinopathy \\
\hline PDGF & Platelet derived growth factor \\
\hline PDL1 & Programmed death-ligand 1 \\
\hline PEDF & Pigment epithelium-derived factor \\
\hline PGE2 & Prostaglandin E2 \\
\hline PGE2R & Prostaglandin E2 receptor \\
\hline PMSCs & Placenta derived mesenchymal stem cells \\
\hline RGCs & Retinal ganglion cells \\
\hline rAAV2 & Recombinant adeno-associated virus \\
\hline $\mathrm{RP}$ & Retinitis pigmentosa \\
\hline RPCs & Retinal progenitor cells \\
\hline RPE & Retinal pigment epithelium \\
\hline RPGR & Retinitis pigmentosa GTPase regulator \\
\hline SCOTS & Stem cell ophthalmology treatment study \\
\hline SD & Stargardt's disease \\
\hline SDF1 & Stromal derived factor 1 \\
\hline SPARC & Secreted protein rich in cysteine \\
\hline STZ & Streptozotocin \\
\hline TGF $\beta 1$ & Transforming growth factor $\beta 1$ \\
\hline TIMP1 & Tissue inhibitor of metalloproteinase 1 \\
\hline TLRs & Toll-like receptors \\
\hline $\mathrm{TM}$ & Trabecular meshwork \\
\hline $\mathrm{TNF} \alpha$ & Tumour necrosis factor $\alpha$ \\
\hline Treg & $\mathrm{T}$ regulatory cells. \\
\hline TSG6 & Tumour necrosis factor-stimulated gene 6 \\
\hline TSP1 & Thrombospondin type 1 \\
\hline UMSCs & $\begin{array}{l}\text { Umbilical cord blood derived } \\
\text { mesenchymal stem cells }\end{array}$ \\
\hline VEGF & Vascular endothelial growth factor \\
\hline
\end{tabular}

$\begin{array}{ll}\text { VEGFR1,2 } & \begin{array}{l}\text { Vascular endothelial growth factor receptor 1,2 } \\ \text { WJMSCs }\end{array} \\ & \begin{array}{l}\text { Wharton's jelly derived } \\ \text { mesenchymal stem cells }\end{array} \\ \text { XLRP } & \text { X-linked retinitis pigmentosa }\end{array}$

\section{Introduction}

Mesenchymal stem cells (MSCs) were successfully isolated from several tissue sources such as bone marrow, adipose tissue, dental pulp, umbilical cord blood, amniotic membrane and considered as promising candidates for therapy to regenerate and repair the degenerated retinal cells in several retinal degenerative disorders [1]. The important reasons for considering MSCs as suitable option for treatment of retinal disorders are, firstly, the paracrine signaling through secretion of neurotropic factors for repair of neuro-retinal cells, secondly, MSCs possess immunomodulatory properties that can dampen the pro-inflammatory microenvironment common to the retinal degenerative diseases and thirdly, their ability to secrete anti-angiogenic factors to inhibit the proangiogenesis involved in the etiology of certain ocular diseases [2].

Although, conventional therapies such as surgery and ocular drugs can slow the progression of the ocular diseases, novel approaches including stem cells and gene therapy have the potential to regenerate the damaged retinal architecture. Several cell therapy approaches were aimed to augment endogenous retinal regeneration by retinal pigment epithelium (RPE) cells and möller glia cells, as well as cell replacement therapy with the help of embryonic stem cells (ESCs), induced pluripotent stem cells (iPSCs), mesenchymal stem cells (MSCs) and retinal progenitor cells (RPCs) [3]. This review will focus on utilizing MSCs for treating retinal diseases and some of the advantages in utilizing MSCs for therapy. This review includes, firstly, some of the common retinal degenerative diseases and the conventional treatments that are administered for these diseases; secondly, the pre-clinical studies that have tested MSCs for the treatment of retinal diseases and finally, we will discuss the outcome of some of the clinical trials utilizing MSCs, where positive therapeutic outcomes were observed.

\section{Age-related macular degeneration (AMD) and Stargardt's disease (SD)}

AMD is a degenerative disease with several genetic and environmental factors contributing to the disease pathogenesis [4]. The advanced stage of AMD comprises of two forms, geographic atrophy (GA) or dry AMD and choroidal neovascularization (CNV) or wet AMD. GA is characterized by the degradation of the retinal pigment epithelium (RPE) layer and Bruch's membrane, the basement membrane, followed by loss of 
photoreceptors as the damaged RPE layer fails to phagocytose the photoreceptor outer segments. Incomplete phagocytosis leads to accumulation of a lysosomal protein lipofuscin, which interferes with the proper functioning of the RPE layer. Accumulation of drusen, the cell debris between the RPE layer and Bruch's membrane causes its detachment inducing progression towards CNV or wet AMD. CNV manifests as abnormal and undesired leaky capillaries across the ocular tissue that leads to fluid accumulation and hemorrhage at the macula [5]. Stargardt's disease (SD), a hereditary disease, is characterized by macular degeneration, and occurs within the first two decades of human life [6]. The most common form of this disease involves mutation in the ABCA4 (ATP-binding cassette, subfamily A , member 4) gene [7], the dysfunction of which causes accumulation of N-retinylidene-N-retinyl-ethanolamine, a major component of lipofuscin, which has a detrimental effect on RPE and photoreceptor cells [8]. Molday et al reported that degeneration of foveal RPE, cone photoreceptors and loss of central vision in Stargardt patients is due to ABCR mutations [9]. Anti-VEGF (vascular endothelial growth factor), photodynamic and laser photocoagulation therapy are administered for wet AMD in order to alleviate neovascularization $[10,11]$. Gene therapy approaches include recombinant adeno-associated virus (rAAV2) vectors carrying soluble fms like tyrosine kinase 1 (sFlt1) $[12,13]$ or chimeric protein such as sFlt01 $[14,15]$, that prevent VEGF binding to endothelial receptors Flt1 (VEGFR1) and Fmk1 (VEGFR2) to reduce neovascularization in wet AMD has been tested by several groups [16, 17]. Song et al reported that subretinal transplantation of human embryonic stem cell (hESC)-derived RPE cells was well tolerated in AMD patients $[18,19]$ and patients with Stargardt's disease as also reported as Schwartz et al $[20,19]$. Although iPSCs have attracted preclinical and clinical studies, autologous transplantation of human iPSCs derived RPE cells resulted in no significant clinical improvement in the AMD patient tested [21,22].

\section{Retinitis Pigmentosa (RP)}

Retinitis Pigmentosa (RP), a hereditary degenerative disorder has autosomal recessive [23], autosomal dominant [24] or Xlinked recessive inheritance patterns [25]. While the initial stages of the disease involves destruction of the rod photoreceptors causing loss of night vision and limited peripheral vision, further progression to later stages results in degeneration of cones leading to loss of central and color vision [26]. The degeneration of photoreceptors in RP is usually associated with gene mutations. Until date, $\sim 4500$ mutations have been discovered in 70 genes involved in the causation of RP [27]. RP is linked with Usher Syndrome, Bardet-Biedl Syndrome, and can also exist as nonsyndromic RP [28]. Pathogenesis of autosomal recessive RP is due to mutation in genes involved in photo-transduction pathway like cGMP phosphodiesterase (PDE6) [29], and intraocular delivery of recombinant Adeno-associated virus
(rAAV) containing corrected PDE6 gene, led to disease remission in mouse disease models [30]. Since, mutation in Mer receptor tyrosine kinase (MERTK) is also known to play a role in autosomal recessive RP [31], gene replacement through AAV vector have resulted in improvement in retinal function in RP models as well as human patients [32,33]. Gene therapy tested for autosomal dominant RP include rAAV carrying ribozymes designed to specifically inhibit mRNA of defective rhodopsin gene [30]. Positive outcomes were reported in X-linked RP (XLRP), caused by mutant retinitis pigmentosa GTPase regulator (RPGR) when treated with AAV8 vectors expressing normal RPGR gene [34]. The first in vivo gene therapy to be approved by Food and Drug Administration (FDA) for RP is, Luxturna, a AAV2 virus carrying the complementary DNA (cDNA) of the gene RPE65, whose biallelic mutation causes recessive RP [35]. FDA also approved transplantation of an artificial retina, resulting in recovery of vision in late-stage RP patients [36, 37]. RP patient-derived iPSCs corrected for mutations in Pro23His variant of rhodopsin (RHO) gene and homozygous Alu insertion in exon 9 of male germ cell-associated kinase (MAK) gene by CRISAP/Cas9 mediated gene editing was proposed for autologous retinal cell replacement. Correction of RPGR gene by CRISPR/Cas9 gene editing also resulted in repair of defective photoreceptors and ciliopathy in the patient iPSC-derived organoids [38, 39].

\section{Diabetic Retinopathy (DR)}

Defined as a multifactorial microvascular disease, DR is induced by chronic hyperglycemia and a consequent sequence of abnormal metabolic events [40] bringing about an overproduction of reactive oxygen species (ROS) [41]. Early or nonproliferative stage of DR (NPDR) is characterized by loss of pericytes, endothelial cells and neuronal cells in the retina [42]. Progression to a more severe stage, the proliferative stage of DR (PDR), results in pro-angiogenic and inflammatory responses, forming intra-retinal vasculature abnormalities and hemorrhages [43]. Since PDR is due to neovascularization, standard treatment methods attempt to lessen uncontrolled angiogenesis by anti-VEGF administration [44]. Expression of an array of anti-VEGF molecules such as, sFlt-1 [45], Flt23k [46], endostatin [47], calreticulin antiangiogenic domain (CAD 180), CAD-like peptide 112 (CAD 112) [48] through viral vectors have resulted in favorable prognosis of DR. Similarly, in a preclinical study, when iris and RPE cells were transfected with pigment epithelium derived factor (PEDF), the CNV reduced by $50 \%$ [49]. Other gene therapeutic strategies that resulted in positive outcomes include viral mediated prolonged expression of human erythropoietin gene that protected the blood retinal barrier (BRB) and retinal neurons in experimental DR rats [50], soluble membrane-independent form of CD59 (sCD59) expression leading to $60 \%$ reduction in the leakiness of retinal blood 
vessels in diabetic mice by blockage of membrane attack complex (MAC) deposition [51] and manganese dependent superoxide dismutase (MnSOD) expression resulting in reduction of intra-ocular ROS levels which prevented progression of DR [52]. Moreover, AAV2 mediated overexpression of retinal angiotensin converting enzyme 2 (ACE2), an intermediate in the renin angiotensin aldosterone system (RAAS) pathway, conferred prevention and partial reversal of the DR associated increase in RAAS signaling as well as the subsequent detrimental effects on the vasculature [53].

\section{Glaucoma}

Glaucoma is characterized by a significant elevation in intraocular pressure (IOP), which leads to progressive death of RGCs, degeneration of the optic nerve head and subsequent vision loss [54]. This rise in IOP is related to degeneration and fibrosis of the trabecular meshwork (TM). Under normal conditions, the role of TM is to drain the aqueous humor, the dysfunction of which leads to open-angle glaucoma and the blockade of TM due to abnormal anatomical location of iris leads to angle-closure glaucoma [55]. Other factors that lead to RGCs damage in glaucoma are hypoxia, ischemic insult, deprivation of nutrients and energy, neuroinflammation, reduction in transmission of neurotrophic factors and chronic neurotoxicity which occur as a consequence of neuronal damage associated buildup of extracellular glutamate, free radicals and excitatory amino acids. Glutamate induced exicitotoxicity leads to disruption of anterograde and retrograde axonal transport and axotomy-induced death in RGCs [54].

Reduction of IOP by pharmacological agents or surgical techniques such as trabeculectomy, non-penetrating glaucoma surgery, micro-invasive glaucoma surgery and glaucoma drainage implants have so far been the primary mode of therapy to prevent disease progression in glaucoma [56]. Minimally invasive ab-interno trabeculectomy which involves removal of the TM via an electro-ablative procedure has shown to have long-term effectiveness in lowering IOP in glaucoma patients [57]. Gene therapy methods to reduce IOP and provide neuroprotection by expression of neurotrophic factors has emerged as an alternative therapeutic option, however the major challenge for gene therapy is the multiple pathogenic mutations associated with glaucoma [58]. Although no gene therapy method has resulted in good clinical outcome in glaucoma [59], a novel gene therapy construct expressing brain derived growth factor (BDNF) and it's receptor tropomyosin receptor kinase B (TrkB) [60] exhibited neuroprotection in experimental glaucoma models [61]. CRISPR/Cas9 gene editing method utilized to disrupt aquaporin 1 gene in ciliary body epithelium cells also resulted in lowering of IOP in an experimental glaucoma model [62].

\section{MSCs for treatment of retinal disorders}

In this section, we discuss some significant properties of MSCs such as the paracrine factors secreted by the cells, the exosomes and mitochondrial transfer into host cells that facilitate the repair and regeneration of retinal layer.

\section{Paracrine neuroprotective factors}

The secretome of bone marrow derived mesenchymal stem cells (BMSCs) contain an array of neurotrophic factors (NTFs) such as ciliary neurotrophic factor (CNTF), BDNF, glial cell derived neurotrophic factor (GDNF), platelet derived growth factor (PDGF), nerve growth factor (NGF), neurotrophin-3, 4/5 (NT-3, 4/5) [63], insulin-like growth factor 1 (IGF1), basic Fibroblast growth factor (FGF2), PEDF and erythropoietin (EPO) [64]. The neurotrophic factors secreted by BMSCs, bind to their cognate receptors on the recipient cells [65] and enhance the neural cell survival, differentiation, axonal outgrowth, neural cell attachment and inhibit neural cell apoptosis $[66,65]$. The signaling pathways activated by the NTFs, such as P13K/AKT, P13K/IAP, PLC/IP3/ PKC, MAPK/ERK and JAK/STAT3 have neuroprotective effect on the neuro-retinal cells $[67,65]$. The neuroprotective role was demonstrated in an ex vivo study by Cui et al, where co-culturing BMSCs with RGCs reduced hydrogen peroxide $\left(\mathrm{H}_{2} \mathrm{O}_{2}\right)$ induced injury in RGCs through the expression of neurotrophins, BDNF, CNTF and reduced the expression of pro-inflammatory factors interleukin $1 \beta$ (IL1 $\beta$ ) and tumor necrosis factor $\alpha(\mathrm{TNF} \alpha)$ by RGCs [68]. Moreover, Osborne et al and Johnson et al found that PDGF secreted by BMSCs protected RGCs in an ex vivo and preclinical models respectively $[69,67]$. Mead et al proposed that NGF, BDNF and NT-3 secreted by BMSCs have protective effects on RGCs [63] and this neuroprotective effect induced by BMSCs was ablated when tropomyosin related kinase (TrK) $[70,71]$ and PDGF receptor $\alpha($ PDGFR $\alpha)$ [69] were inhibited on RGCs. Intravitreal transplantation of GDNF and BDNF secreting BMSCs resulted in higher number of RGCs compared to the control group in an experimental optic nerve crush model [72]. Similarly, long-term neuroprotection and axon regeneration of RGCs was observed after transplantation of BMSCs, which was attributed to an increased expression of FGF2 and IL1 $\beta$ in the RGC layer that activated the PI3/AKT signaling cascade and rescued RGCs [73]. Martin et al found a significant increase in neuroprotective (D114, Crim-1, Glupican-3, Cntn1), anti-inflammatory (Transforming Growth Factor $\beta$ and IL10, 13, 11, 4) molecules as well as proteins associated with anti-oxidant (haptoglobin), antiapoptotic (Apex1) activity and protein homeostasis (Hsp10, Hsp60, Hsp70, Hsp20, Hsp27, Kctd10, Pyk2, clusterin) in the secretome of human BMSCs co-cultured with neuroretinal explants [64]. 
Similar to BMSCs, adipose derived mesenchymal stem cells (ADSCs) secrete a repertoire of NTFs such as hepatocyte growth factor (HGF), CNTF, IGF [74], FGF2, epidermal growth factor (EGF) [75], VEGF, NGF, BDNF, GDNF, NT3 , and PDGF [76]. Ezquer et al found that intravitreal administration of murine ADSCs resulted in significant increase in intraocular levels of NGF, FGF2 and GDNF, prevented RGC loss and reduced oxidative stress in the retina in a diabetic mouse model. In addition, the injected cells also differentiated into RGCs, astrocytes and pericytes in vivo [77]. Further, conditioned media from human ADSCs protected RPE and photoreceptor cells from oxidative stress mediated cell death [78] and inhibited retinal damage in vitro and in vivo [79]. Progranulin, tissue inhibitor of metalloproteinase 1 (TIMP1), the secreted protein rich in cysteine (SPARC) $[79,80]$ and HGF [78] present in the ADSCs conditioned media played an important role in neuroprotection. On the other hand, treatment of ADSCs with conditioned media of RPE cells under oxidative stress enhanced the migration rate of ADSCs, through SDF1 and CXCR4 mediated interaction between RPE cells and ADSCs, respectively [78].

Mead et al found that human dental pulp derived mesenchymal stem cells (DPSCs) secreted higher levels of PDGF, NGF and prostaglandin E2 receptor (PGE2R) than human BMSCs and ADSCs [71]. Further, DPSCs transplantation resulted in significantly high number of brain specific transcription factor 3a (Brn3a) positive RGCs, increased retinal nerve fibre layer thickness and improved RGC function in an openangle glaucomatous preclinical model [81]. Ji et al found that the human umbilical cord blood derived mesenchymal stem cells (UMSCs) mainly exhibited neuroprotective properties through secretion of BDNF and GDNF in an ocular hypertension animal model [82]. In addition, Zhang et al reported that human UMSCs derived neural stem cells (NSCs) when transplanted in a STZ-induced DR model increased the survival of RGCs and reduced the progression of DR [83]. Wharton's jelly derived mesenchymal stem cells (WJMSCs) were reported to delay axotomy-induced death of RGCs when stimulated to release neuroprotective and immunomodulatory factors by the cues present in the microenvironment of the injured retina [84].

\section{MSC derived extracellular vesicles (MSC-EVs)}

MSC-EVs or exosomes are secreted, bilipid layered, nano dimensional micro vesicles which encapsulates functional molecules such as proteins, lipids, miRNAs and can provide important therapeutic effects. MSC-EVs were found to be endocytosed by retinal neurons, microglia and RGCs via caveolar mediated endocytic pathway, facilitated by heparin sulfate proteoglycans (HSPGs). Furthermore, the endocytosis of MSC-EVs took place in a dose, temperature dependent manner and saturable interaction of MSC-EVs with proteins of the vitreous humor was responsible for prolonged retention of EVs in the eye [85]. Yu and co-workers showed that intravitreally injected MSC-EVs were as efficient as transplanted MSCs in reducing damage and apoptosis in addition to improving vision in an experimental model of retinal laser injury. Moreover, MSC-EVs ameliorated retinal damage by downregulating the expression of pro-inflammatory mediators, intercellular adhesion molecule 1 (ICAM1), monocyte chemoattractant protein 1 (MCP1), TNF $\alpha$ [86] and VEGF-A [87]. Studies by Mead et al showed that BMSCs derived exosomes prevented death of RGCs and preserved more than $50 \%$ of RGC function in a rat optic nerve crush model [88]. This was found to be orchestrated by miRNA dependent mechanism where the positive effects on RGC declined when Argonaute2, a protein necessary for miRNA biogenesis was knocked out in experimental models of glaucoma [89, 90]. Safwat et al reported beneficial role of micRNA-222, shuttled in ADSCs derived exosomes, for retinal repair in a diabetic rabbit model. Hyperglycemia, which leads to decreased expression of micRNA-222, is associated with acute retinal damage and substantial hemorrhage in different layers of retina. Injection of EVs through intravenous (IV), sub conjunctival $(\mathrm{SC})$ and intraocular $(\mathrm{IO})$ routes increased the expression of micRNA-222 in the retina, leading to retinal regeneration [91]. MSCs derived EVs can negate the demerits of cell-based therapy like transplantation failure, immunogenic, oncogenic risks and opens further opportunities to engineer artificial, function specific EVs to achieve neuroprotection and retinal regeneration.

\section{MSCs dampen inflammatory responses}

The ability of the eye to prevent intraocular inflammation in order to protect the visual elements from damage and thus, conserving visual acuity, is defined as ocular immune privilege [92]. This highly complex phenomenon is maintained by the BRB which efficiently separates the eye from the immune system along with local inhibition of both innate and adaptive immune responses by the ocular microenvironment, and ocular-specific mechanisms cause systemic activation of immunosuppressive regulatory $\mathrm{T}$ cells [93]. Ocular fluids contain suppressors of natural killer (NK) cell function, namely, macrophage migration inhibitory factor (MIF) and transforming growth factor $\beta$ (TGF $\beta$ ); neuropeptides, alphamelanocyte stimulating hormone $(\alpha-\mathrm{MSH})$ and calcitonin gene-related peptide (CGRP) which dampen the activation and the function of macrophages; complement factor $\mathrm{H}$ $(\mathrm{CFH})$, decay accelerating factor (DAF) and Crry, proteins involved in regulation of the complement system [94]. Further, expression of molecules such as Fas ligand (CD95), programmed death-ligand (PDL1), cytotoxic T-lymphocyte antigen-4 (CTLA-4) and CTLA-2 by ocular cells, especially the ciliary body, iris and RPE cells, control the adaptive 
immune cells, hence generating an immunosuppressive ocular microenvironment [95]. However, pathological conditions such as AMD, glaucoma and DR, are characterized by an abundance of proinflammatory cytokines in addition to infiltration of immune cells leading to breakage of the BRB [96].

The inflammatory response involved in the etiology of AMD, has a significantly small magnitude and tempo, a phenomenon broadly known as "para-inflammation". The adaptive immune system is involved in the development of AMD, where complement C5a promotes Th17 mediated inflammation. High levels of IL22 and IL17 in the sera of AMD patients demonstrates the prominence of T-cell involvement [97]. In case of glaucoma however, neuroretinal damage occurs, which is not only due to the amino acid glutamate, but also by a distinctive neuro-inflammatory response via activation of astrocytes and microglial cells, as a consequence of recognition of pathogen associated molecular patterns (PAMPs) and damage associated molecular patterns (DAMPs). Toll-like receptors (TLRs) expressed by astrocytes and microglial cells, activate the secretion of cytokines of the IL1 family, which in turn promotes the production of a secondary cascade of inflammatory cytokines, such as secretion of IL6 by astrocytes and TNF $\alpha$ by microglia, which leads to a heightened inflammatory response [98]. Hyperglycemic condition in DR activates a number of glucose metabolic pathways, which indirectly results in an upregulation of pro-inflammatory and angiogenic factors, leading to an aberrant inflammatory response and endothelial dysfunction. Activation of retinal glial cells including astrocytes, müller cells and microglia play a significant role in the onset of inflammation at the later stages of DR [99]. Several studies have shown that MSCs have the ability to selectively suppress immune responses, only when placed within a pro-inflammatory microenvironment and hence have been suggested for therapy for patients with severe immunological disorders [100]. The mechanism of immunosuppression by MSCs involves cell-cell contact mediated repression of function and maturation of T cells (CD4+ and CD8+ cells), B cells, dendritic cells (DCs), NK cells, neutrophils and macrophages [101]. Functional regulation of these immune cells and anti-inflammatory responses by MSCs is triggered by secretion of immune-modulatory cytokines such as, nitric oxide (NO), indoleamine 2,3- dioxygenase (IDO), tumour necrosis factor-stimulated gene 6 (TSG6), prostaglandin E2 (PGE2), thrombospondin type 1 (TSP1), interleukins 6, 10 (IL6, IL10), TGF $\beta 1$, and HGF [102]. Further, MSC derived exosomes modulate inflammation by promoting polarization of macrophages from the pro-inflammatory M1 phenotype to the anti-inflammatory M2 phenotype, activation of regulatory $\mathrm{T}$ (Treg) cells, inhibition of B lymphocytes and prevention of neutrophil mobilization [103, 104].

Studies have shown that intravitreal and periorbital administration of BMSCs resulted in significant reduction of inflammatory cytokines in the retinal microenvironment, infiltration of macrophages [105] and $\mathrm{CD} 4^{+} \mathrm{T}$ cells [106]. Moreover, when stimulated with IL17 and IFN $\gamma$ (Interferon $\gamma$ ), the high expression of pro-inflammatory factors observed in organotypic cultures of the posterior segment of the eye was significantly thwarted in the presence of murine BMSCs [107]. Further, injection of rat BMSCs impeded the Th1/ Th17 mediated inflammation, regulated the equilibrium between Th17 and Tregs, and decreased the function of antigen presenting cells (APCs) in an experimental autoimmune uveitis model [108]. Transplantation of rat ADSCs in an experimental ocular hypertension model led to reduced expression of pro-inflammatory cytokines, IFN $\gamma, \mathrm{TNF} \alpha$ and increased the expression of anti-inflammatory cytokines, prostaglandin E2 receptor and IL1Ra [109]. Ji et al found that intravitreally injected human UMSCs attenuated retinal neuroinflammation by downregulation of TLR4 signaling pathway in a glaucomatous rat model [110]. Moreover, intravitreally administered rat BMSCs decreased the levels of proinflammatory cytokines TNF $\alpha$, IL $\beta 1$ and IL 6 and abrogated ischemia-induced damage in the retina in a preclinical model reported by Mathew et al [111]. Holan et al and Cejkoa et al reported a marked suppression in the infiltration of T lymphocytes and levels of pro-inflammatory cytokines after transfer of rabbit derived MSCs onto an alkali-injured ocular surface $[112,113]$. Millan-Rivero et al reported that human WJMSCs expressed a higher level of immunomodulatory factors TGF $\beta$, IDO, PGE2 than BMSCs and elicited neuroprotection [84].

\section{MSCs modulate angiogenesis}

Pathological retinal angiogenesis, unlike vasculogenesis and physiological angiogenesis, leads to disorderliness and creates physiologically deficient blood vessels that disrupt the neuronal histology. These newly formed blood vessels intrude into the outer retina and the macular pit, where absence of vascularity is essential for human vision. Retinal diseases like AMD, diabetic retinopathy, uveitis and retinal vasculitis are characterized by pathological angiogenesis leading to permanent loss of vision [114]. Kim et al reported that intraperitoneal injection of human placental amniotic membrane derived MSCs (AMSCs) in a mouse model of oxygen induced retinopathy resulted in significant abrogation of neovascularization through TGF $\beta 1$ expression, which was blocked when AMSCs were transfected with TGF $\beta 1$ siRNA [115]. Ghazaryan et al reported that sub-conjunctival injection of BMSCs encouraged corneal wound healing and significantly reduced the neovascularization by downregulating VEGF and matrix metalloproteinase-9 (MMP-9) expression [116]. When murine ADSCs were intravitreally administered in a diabetic mouse model, although the intraocular levels of VEGF and PDGF was unaffected, the expression levels of TSP1 increased significantly [77]. TSP1, primarily produced by RPE, choroid and möller glial cells in the healthy eye prevents 
VEGF receptor 2 (VEGFR2) activation by disrupting the receptor's association with $\mathrm{CD} 47$ and terminates the VEGF signaling to AKT- endothelial nitric oxide synthase pathway [117, 118]. TSP1 also binds to CD36 and recruits Src homology 2 domain- containing protein tyrosine phosphatase (SHP1) to the CD36-VEGFR2 complex in the microvascular endothelial cells, which in turn dephosphorylates VEGFR2 and inhibits angiogenesis [119]. Several studies have suggested that the successful reconstruction of damaged ocular tissues by MSCs was more dependent on the release of paracrine anti-inflammatory and anti-angiogenic factors than differentiation into ocular cells [120-122]. Thus, when human BMSCs were intravitreally implanted in an oxygen induced retinopathy mouse model, it significantly reduced retinal neovascularization [123]. When engineered to secrete therapeutic dose of anti-angiogenic factor PEDF, BMSCs were recruited to $\mathrm{CNV}$ lesions and inhibited neo-angiogenesis in vivo [124]. Although MSCs secrete pro-angiogenic factors VEGF and PDGF, which in fact can accelerate pathological angiogenesis in retinal diseases, it was found that MSCs exert either pro- or anti-angiogenic effect depending on the tissue microenvironment into which they were transplanted [77, 125].

\section{MSCs donate mitochondria}

Several studies have reported that MSCs transfer healthy, functional mitochondria via tunneling nanotubes (TNTs) [126], gap junctions [127] and exosomes [128, 129] to the damaged cells for its regeneration [130]. Numerous studies have demonstrated enhancement of mitochondrial bioenergetics by MSCs in the injured cells in spinal cord [131], bronchial epithelia [132, 133], corneal epithelia [134], cardiomyocytes [135, 136] and cells affected by neurotoxicity [137, 138]. Ndufs4 knockout mouse model, characterized by mitochondrial complex I dysfunction, suffer from RGC degeneration, a condition which is strongly linked to proinflammatory and innate immune responses. When induced pluripotent stem cell-derived mesenchymal stem cells (iPSC-MSCs) were injected intravitreally into Ndufs4 knock out mouse, MSCs donated mitochondria to damaged RGCs via TNT formation and rescued its function. Although, injected MSCs do not pass through inner limiting membrane (ILM) of the retina, the mitochondria donated by the MSCs efficiently permeated the ILM and limited the RGC death [139]. Mitochondrial dysfunction is involved in many retinal diseases such as AMD, DR, glaucoma and mitochondrial transfer therapy might have profound impact for the treatment of these diseases [140].

\section{MSCs replace pericytes}

Pericytes are a heterogenous population of cells in the blood vessels [141], embedded in the basement membrane of the vasculature, provides protection and stabilize the retinal microvasculature [142]. Vasoregression caused due to loss of pericytes induced by hyperglycemia, is a major cause of pathogenesis in DR [143]. Several studies have suggested that MSCs could replace pericytes [77, 144], due to the morphological and functional similarities of MSCs with pericytes [145] and thus MSCs can provide therapeutic advantage in the early stage DR [146]. Adipose tissue derived stromal cells (ASCs), isolated from the stromal vascular fraction of the adipose tissue, shares cell surface markers expression with both MSCs and pericytes [147]. ASCs were found located at perivascular locations in the adipose tissue and expressed genes characteristic of pericytes [148], stabilized the vasculature and prevented apoptosis of endothelial cells. NOTCH2 was found to be essential for ASCs to acquire pericyte position in the retinal microvasculature in vivo whereas its regenerative capacity was unaffected by $\mathrm{NOTCH} 2$ downregulation [149]. Mendel et al found that intravitreal injection of ASCs in oxygen induced retinopathy mouse model and Akimba diabetic mice models resulted in integration of the injected cells in the retinal microvessels and exhibited pericyte like function. The injected cells normalized retinal microvasculature and prevented capillary loss in these disease models [144]. Further, Rajashekhar et al found that intravitreally injected human ASCs in a chronic hyperglycemia DR model aligned themselves with the host vasculature, rescued the neural retina degeneration and improved visual function, suggesting pericyte-like function of the injected cells [150].

The property of human ADSCs to stabilize retinal vasculature remains unaltered, in the hyperglycemic or diabetic environment generally found in DR [151-153]. Fiori et al found that ADSCs supported angiogenesis under hyperglycemic conditions while their differentiation ability and cell surface marker expression remain unaffected. In agreement with the angiogenesis supporting ability, the ADSCs acquired pericyte-like function when co-cultured with endothelial cells [151]. However, treatment with ADSCs might be beneficial only in the early stages of DR during vasoregression and can be detrimental in the late stage of DR characterized by neoangiogenesis.

\section{Differentiation of MSCs into retinal cells}

BMSCs, ADSCs, DPSCs and UMSCs have been found to efficiently differentiate into various cells of retinal lineages in vitro and express genes related to retinal cells. Some studies also tested the functionality of the differentiated cells in in vitro systems. Autologous MSC transplantation could be a promising strategy for cell replacement therapy in retinal 
diseases, however, further preclinical studies are required to understand the safety, immunogenicity and function of the transplanted cells in vivo.

\section{BMSCs}

When cultured in the presence of retinal extract and supernatant from T-cell mitogen Concanavalin A-stimulated splenocytes, murine BMSCs differentiated and expressed genes related to several retinal cell types such as photoreceptors (rhodopsin, S antigen, recoverin), horizontal and bipolar cells (calbindin2), RPE cells (retinaldehyde binding protein) and müller cells (retinaldehyde binding protein, retinal pigment epithelium 65) [154]. Further, rat BMSCs cultured in conditioned media from neonatal rat retinal cells differentiated into RGC-like cells which stained positive for nestin, neurofilament, Map2, Thy1.1 and exhibited protein expression patterns similar to that of isolated RGCs [155]. Co-culturing of human BMSCs with adult pig RPE cells in a transwell system resulted in differentiation of MSCs into cellular retinaldehyde binding protein (CRALBP), retinal pigment epithelium 65 (RPE65) and zonula occludins-1 (ZO-1) positive cells, secreted BDNF, GDNF and showed the ability to phagocytose extracellular elements of the photoreceptor outer segments in vitro [156]. Also, RPE-like cells that expressed RPE65 with phagocytic activity was generated from BMSC derived neurospheres in an in vitro study reported by Kadkhodaeien et al [157].

\section{ADSCs}

Huang et al reported in vitro differentiation of human ADSCs into retinal progenitors, RGCs and photoreceptors cells expressing characteristic retinal cell markers when treated with noggin, dickkopf related protein-1, IGF-1 and exhibited glutamate-evoked calcium response [158]. Amirpour et al reported that culturing human ADSCs in the presence of small molecule inhibitors of WNT, NODAL and BMP4 signaling pathways, or ADSCs derived conditioned media or with both the inhibitors and the conditioned media resulted in the differentiation of ADSCs into eye-field neuroectoderm (EFN) cells expressing OTX2, or cells expressing high levels of PAX6, RAX and SIX3 or cells with high expression of $\beta$-tubulin III respectively [159]. However, hanging drop cultures of ADSCs with the above conditions resulted in higher expression of EFN markers compared to monolayer cultures [160]. Similar to that observed in BMSCs, human ADSCs cultured with conditioned medium from RPE, showed the ability to differentiate into cells expressing typical RPE markers RPE65, cytokeratin 8, bestrophin and acquired high proliferative and migratory ability in vitro [161]. Rezanejad et al noted that the ADSCs transduced with human transcription factor Paired box 6 protein (PAX6, 5a) and cultured in a media supplemented with fibronectin differentiated into retinal progenitors, photoreceptors and RPE cells expressing cone-rod homeobox protein (CRX), rhodopsin and RPE65 [162].

\section{DPSCs and UMSCs}

Roozafzoon and colleagues found that DPSCs successfully differentiated into RGCs-like cells when cultured in a media containing FGF2, sonic hedgehog (Shh) on a biocompatible fibrin hydrogel (3D culture). The differentiated cells expressed astrocyte marker GFAP, neuronal marker MAP2, RGCs specific marker Brn3b, Pax6 and atonal bHLH transcription factor 7 (Atoh7) [163]. Further, ex vivo expansion of DPSCs in conditioned media obtained from chemically damaged rat retina resulted in morphological changes and expressed rhodopsin and BDNF [164].

Choi et al reported that when UMSCs were cultured in retinal differentiation inducing media with anti-miR-203, the cells exhibited a significant increase in expression of retina development genes (CRX, NRL and DKK1), and differentiated into cone photoreceptor-like cells with expression of OPN1MW, rod photoreceptor-like cells and expressed NR2E3, NRL, and Rhodopsin. [165]. Similarly, inhibition of miR-410 in UMSCs induced differentiation into RPE-like cells that expressed bestrophin and EMMPRIN, and exhibited phagocytosis ability [166].

\section{Genetically engineered MSCs}

Several research groups have genetically modified MSCs and tested their efficiency in treatment of retinal diseases in animal models and in vitro studies. Intravitreally injected murine BMSCs engineered to secrete BDNF was found integrated into the outer retinal layers and rescued damaged retinal cells through activation of anti-apoptotic factor B-cell lymphomaextra-large-protein (BCL-XL) expression in a retinal degenerative rd6 mutant mouse model [167]. Similarly, neurotrophin4 (NT-4) engineered murine BMSCs could be detected 3 months post intravitreal transplantation in a preclinical model of acute retinal injury. Here, the transplanted cells migrated to the sites of injury, resulting in significant improvement in morphology and function of the damaged retinal cells [168]. The presence of BDNF and NT-4 in the damaged retinal microenvironment activated the TrkB expression in the RGCs, which in turn activated the signaling pathways involved in neural cell survival (P13/Akt pathway), differentiation, migration and development (ERK pathway). NT-4 expressing BMSCs also induced the expression of several proteins of the crystalline $\beta-\gamma$ superfamily, known to be actively involved in neuroprotection [168]. When Guan et al injected genetically modified rat BMSCs that secrete EPO in a retinal degenerative rat model, retinal morphology, function 
improved significantly and the transplanted MSCs adopted RPE morphology [169]. EPO possesses anti-apoptotic, antioxidative, anti-inflammatory, neuroprotective properties [170] and can also enhance regenerative potential of engineered MSCs in an autocrine manner. Conditioned media from EPO expressing WJMSCs ameliorated glutamate-induced cell death in human retinal neurons in vitro [171] and placenta derived MSCs (PMSCs) expressing PEDF caused regeneration of oxidative stress damaged RPE cells when co-cultured in vitro or injected intravitreally in vivo [172].

MSCs require a niche for survival, differentiation and integrating them with a 2D or 3D biomaterial derived scaffold can mimic endogenous ECM and might result in superior in vivo integration. Hyaluronic acid (HA), a substance physically and chemically similar to the vitreous body of the eye, when intravitreally injected along with MSCs in a rat model of glaucoma, it promoted integration of MSCs into the basement membrane of müller glial cells and enhanced survival of RGCs by inducing the expression of NGF and BDNF [173]. Moreover, 3D cultures of DPSCs on biocompatible fibrin hydrogel [163], culturing BMSCs on silk fibroin films functionalized with integrin-binding laminin peptide motifs (GYIGSR and YIGSR) [174], culturing MSCs on amniotic membrane scaffold and differentiation of human conjunctival MSCs (CMSCs) towards photoreceptor like cells on fibrin hydrogel [175] resulted in significant enhancement of MSCs differentiation into the desired retinal cell types.

\section{Clinical Trials with MSCs for retinal diseases}

The encouraging outcomes seen with injecting MSCs in animal models of retinal degeneration led to initiation of several clinical trials. Whilst most trials are ongoing (Table 1), outcomes of some of the phase I trials are discussed below.

In a case report of SCOTS (Stem cell ophthalmology treatment study) clinical trial (NCT01920867), a patient suffering from autoimmune optic neuropathy prone to relapse, underwent a vitrectomy and intraoptic injection of autologous BMSCs in the right eye along with retrobulbar, subtenon and intravitreal injection of the same cells in the left eye. Significant improvement in visual acuity and visual field was observed 3 months and 6 months after the treatment [176]. In another SCOTS trial, a patient suffering from idiopathic optic neuropathy resulting in significant loss of central vision for approximately 5 years received retrobulbar, subtenon and intravitreal injection of autologous BMSCs in the right eye. The left eye was treated with vitrectomy and intra-optic nerve injection of the same cells, followed by intravenous infusion. The enhancement of visual acuity in both eyes remained stable when examined 12 months postoperation [177]. Weiss and Levy conducted a SCOTS clinical trial in 17 patients suffering from bilateral vision loss due to progressive RP with autologous BMSCs transplantation. A 6 months followup found an improvement in visual acuity in 11 out of 17 patients $(64.7 \%), 8$ patients $(35.3 \%)$ exhibited stability in their condition and none experienced vision loss. This study also found that the ability of the eyes to respond to cell therapy was irrespective of the duration of the disease [178]. However, Satarian et al reported that intravitreal injection of autologous BMSCs in three patients suffering from advanced $\mathrm{RP}$, resulted in improvement in visual acuity in only two of the patients whereas the third patient developed severe and progressive adverse effects. The patient developed vitreal and pre-retinal fibrosis two weeks after transplantation which led to total tractional retinal detachment at the end of the threemonth follow-up period [179]. A prospective, nonrandomized clinical study (ChiCTRONC-16008055) by Gu et al analyzed the safety and effectiveness of intravenous administration of autologous BMSCs. The study included 10 patients with severe NPDR and 7 patients with non-high-risk PDR. During 6 months follow-up, the patients of the NPDR group exhibited significant gain in BCVA (best corrected visual acuity) ( $\mathrm{P}=0.006$ at 3 months and $\mathrm{P}=0.027$ at 6 months) and macular thickness reductions. On the contrary, only a slight BCVA improvement and macular thickening was recorded in the PDR group suggesting that the treatment regime is suitable for patients at NPDR stage, rather than PDR stage [180].

In a clinical trial involving 12 AMD patients, Limoli et al administered autologous adipocytes along with ADSCs obtained from stromal vascular fraction (SVF) and platelet rich plasma (PRP) between choroid and sclera and found a significant improvement in retinal functionality as observed by increased electroretinogram (ERG) values [181]. In the next phase of the trial, ADSCs along with PRP was administered in suprachoroidal space of 36 eyes involving 25 AMD patients. Six months follow up indicated that 19 out of 36 $(52.78 \%)$ eyes exhibited better vision, 14 eyes $(38.89 \%)$ showed no change in functionality, and the condition of three eyes $(8.33 \%)$ worsened. The eyes which possessed greater retinal thickness prior to the treatment were seen to show greater improvement in vision and thus, high number of residual cells can lead to more interaction with paracrine factors secreted by ADSCs and chorio-retinal cell membrane receptors, allowing enhancement in vision quality [182]. Oner et al tested the safety and efficacy of subretinal implantation of ADSCs in 11 patients suffering from end-stage RP and found neither improvement nor adverse effects in most of the patients. However, five patients in the study group experienced ocular complication and one patient suffered from CNV [183]. In another phase II study, Oner et al found an improvement in visual acuity, visual field and multifocal electroretinography (mf-ERG) readings after suprachoroidal ADSCs implantation in patients with dry AMD (4 patients) and Stargardt's macular dystrophy (SMD, 4 patients). During the 6 month follow up, 


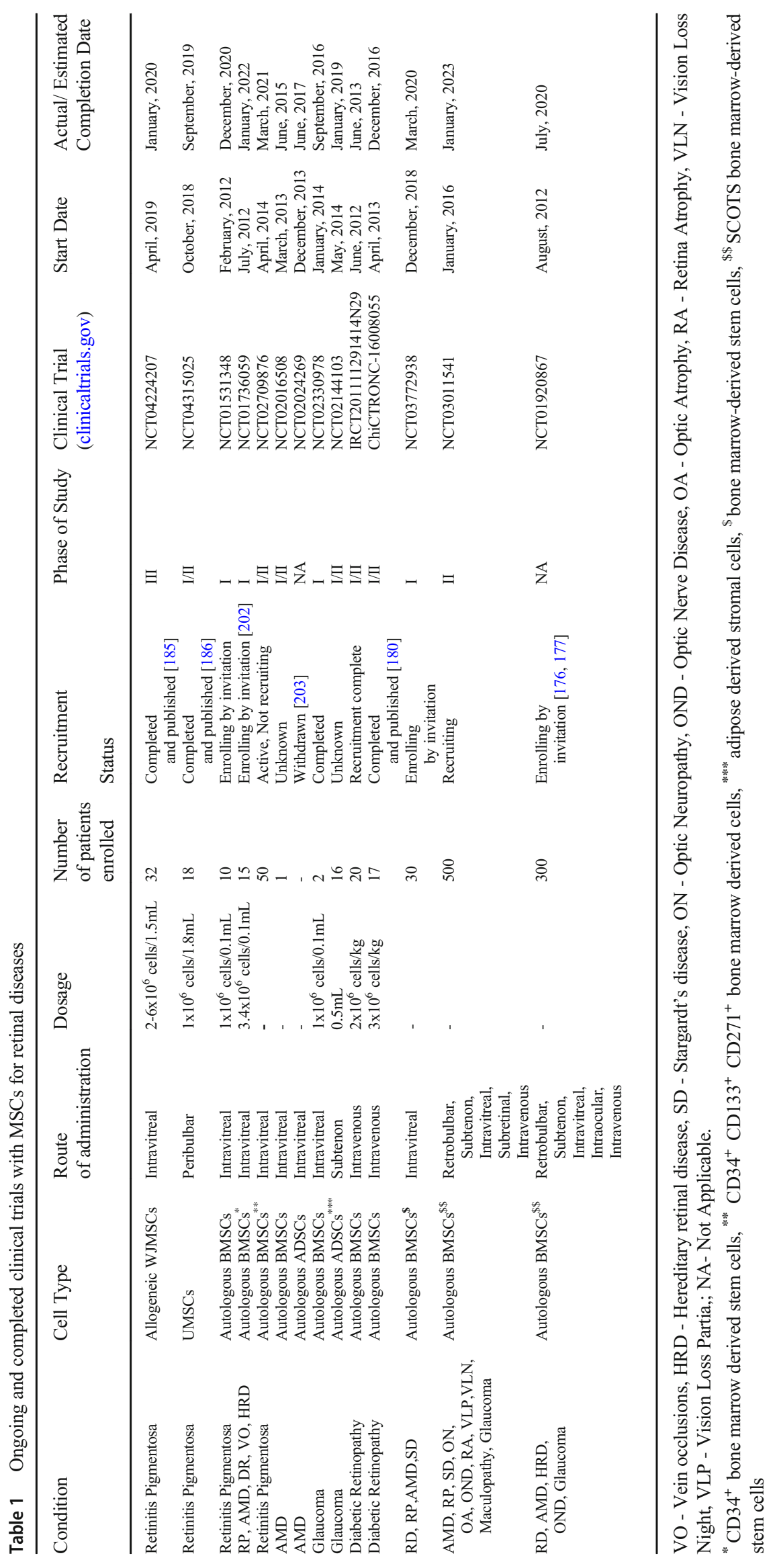


no ocular or systemic complications were observed in these patients [184].

Özmert and Arslan recently reported the result of an open label, phase III clinical trial (NCT04224207) with WJMSCs. In this study, WJMSCs were implanted in the sub-tenon space in 32 patients diagnosed with RP. In the 6 month follow up period, a significant improvement in mean BCVA, outer retinal thickness values, mf-ERG results and decrease in the visual field mean deviation value was observed. The authors did not observe any severe ophthalmic or systemic complication, thus, assuring its safety [185]. Mangunsong et al tested the safety and efficacy of peribulbar infusion of UMSCs in a prospective, multi-center, randomized clinical study (NCT04315025) involving 18 individuals suffering from RP. An improvement in light perception and visus was observed one week after the treatment and no serious side effects was seen during that period [186].

\section{Challenges and future prospects}

Although MSCs are promising therapeutic candidates for retinal degenerative diseases due to their ability to secrete a repertoire of NTFs, modulate inflammation and angiogenesis, regenerate pericytes and donate mitochondria, the therapeutic outcome is limited by poor cell survivability and self-renewal of the cells post-transplantation [187, 188]. For example, although, Inoue et al identified a delay in retinal degeneration after injection of MSCs into RCS rats, they did not find integration of the injected cells into the retinal layer [189]. Several reasons for cell death at the transplanted site have been

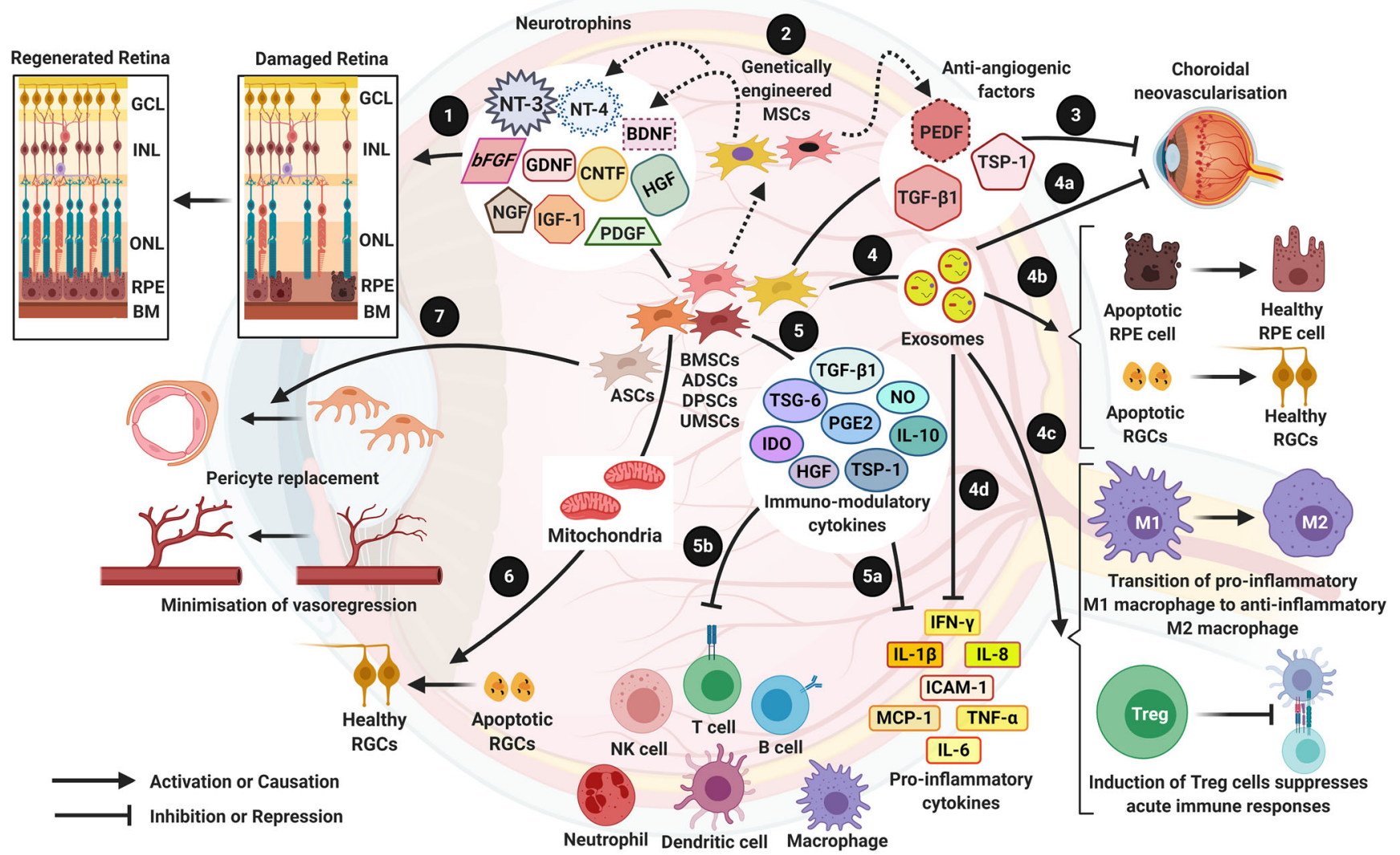

Fig. 1 Mesenchymal stem cells for treatment of retinal degenerative disorders 1) MSCs have the ability to secrete several neurotrophins which play a cytoprotective role in degenerated retina, found in multiple retinal diseases such as AMD, SD, DR, RP, and Glaucoma [63]. 2) MSCs can be genetically engineered to express neurotrophins such as NT-4 [168], BDNF [167] and anti-angiogenic factor PEDF [124] that can improve therapy outcome. 3) AMD and DR are associated with pathological angiogenesis which leads to abnormal growth of blood vessels (Choroidal neovascularisation) and haemorrhages within the ocular microenvironment $[43,198]$. Anti-angiogenic factors released by MSCs can reverse abnormal pathological angiogenesis [77, 115]. 4) MSCs secrete exosomes, microvesicles which contain a cargo of biomolecules such as mRNA, lipids, several proteins with therapeutic advantages: (4a) Exosomes contain anti-angiogenic factors [87] that can inhibit pathological angiogenesis; (4b) mRNA molecules in the exosomes provide neuroprotection of essential retinal cells [88]; (4c) molecules within the exosomes prevent the activation of macrophages and induce Treg cells, hence downregulating disease causing immune responses within the ocular tissue [104]; and (4d) anti-inflammatory factors in the exosomes [86] aid in the recovery of retinal degeneration in AMD, DR and Glaucoma. 5) MSCs secrete immunomodulatory cytokines [102], which (5a) represses the action of pro-inflammatory cytokines and (5b) thwart acute immune responses, both of which are involved in the pathogenesis of AMD, DR and Glaucoma. 6) MSCs provide cytoprotection by donating healthy mitochondria to apoptotic retinal cells through formation of cell-cell contact via tunneling nanotubes or gap junctions [140]. 7) ADSCs can replace pericytes and stabilize vasculature in DR [151]. 
suggested such as exposure to harsh microenvironment featuring hypoxic conditions, oxidative stress or inflammation; lack of extracellular matrix for cell adhesion, thus leading to increased anoikis, mechanical stress during the transplantation procedure or lack of an optimized dosage and protocol for transplantation [187, 188]. Likewise, lack of integration of MSCs after intravitreal injection, might be due to the cells being drained out of the eye with the flow of aqueous humor [190]. Several preclinical studies utilized human MSCs in rat, mouse and rabbit disease models to test their potential use for retinal therapy, however, a major concern is that the diseased ocular environment in these animal models might not be identical to the human diseases [191]. Moreover, the secretome of MSCs in non-human ocular microenvironment might not resemble that of the human conditions and have the risk of overestimating or undervaluing the potential benefits.

Tassoni et al reported an adverse effect, induction of reactive gliosis in response to intravitreal transplantation of MSCs $[192,193]$. This was due to the activation of müller glia cells via JAK/STAT3 and MAPK cascades, resulting in overexpression of intermediate filaments (vimentin, nestin, GFAP) and significant production of neurotoxic Lipocalin-2. Reactive gliosis is characterized by structural disorganization of the retina, infiltration of macrophages and inflammation [193]. Since glial reactivity can act as a deterrent to the retinal engraftment of transplanted MSCs, pharmacological inhibition of STAT3 could prevent the occurrence of reactive gliosis [193]. On the contrary, a subsequent study reported a reduction in gliosis and improvement in visual function within 3 weeks of infusion of MSCs in a STZ-induced diabetic retinopathy model [194]. Hence, the subject of occurrence of reactive gliosis after infusion of MSCs in the diseased ocular tissue needs further investigation and consideration before utilizing the cells for therapy. Further, some of the clinical trials discussed earlier reported adverse effects or worsening of the condition after administration of MSCs [179, 182, 183].

Additionally, the source of MSCs and the age of the donor tend to impact the differentiation and paracrine effects of MSCs, for example, ADSCs were found to secrete VEGF, unlike BMSCs [195]. Some studies have hypothesized that the pro- or anti-angiogenic effect of MSCs depend on the tissue microenvironment [196, 197, 121], and a detailed understanding of the pro or anti-angiogenic niche is also necessary. This is important in utilizing MSCs for ocular disorders where choroidal neovascularization plays a major role in pathogenesis [198]. Additionally, it is known that ASCs are able to replace pericytes and protect the vascular networks within the retina, however, serious considerations should be given before its therapeutic use since the pro-angiogenic ability of ASCs can promote disease progression in DR [199].

Although MSCs have been shown to differentiate into cell types of retinal lineages in several studies in vitro, it is still not clear whether the differentiated cells can exhibit the desired function in vivo. Specifically, the phagocytic ability of the RPE cells derived from MSCs $[166,156,157]$ has to be critically analyzed before concluding the transdifferentiation of MSCs into functional RPE cells. There are some evidences that show that MSCs themselves can perform phagocytosis [200] and the phagocytic assays of RPE cells should include all the essential markers as reported by Mazzoni et al [201]. Nevertheless, secretion of NTFs and paracrine mediated therapy plays a more important role than the trans-differentiation of MSCs in repair of the damaged retinal tissue [63]. In this context, cell free therapy, consisting of conditioned media from cultured MSCs, that contains extracellular vesicles, mitochondria, NTFs and other paracrine factors might have greater clinical benefit as well as eliminate the safety issues associated with injecting the cells at the target site (Fig. 1). Thus, MSCs from different sources have potential benefits for the treatment of retinal disorders, as observed in several preclinical studies and human clinical trials, developing a standardized method for each disease type will help in utilizing these cells efficiently for the benefit of the patients.

Author contributions BGJ conceptualized the idea; SA, DM, SD, DD and BGJ wrote the manuscript and approved the final version of the manuscript.

Funding SA was supported by Ministry of Human Resource Development (MHRD), Govt. of India. This study was partially supported by Indian Institute of Technology Guwahati (IITG).

\section{Compliance with ethical standards}

Conflicts of interest The authors declare that they have no conflicts of interest.

\section{References}

1. Nancarrow-Lei R, Mafi P, Mafi R, Khan W (2017) A Systemic Review of Adult Mesenchymal Stem Cell Sources and their Multilineage Differentiation Potential Relevant to Musculoskeletal Tissue Repair and Regeneration. Current stem cell research \& therapy. https://doi.org/10.2174/ 1574888X12666170608124303

2. Ding SLS, Kumar S, Mok PL (2017) Cellular reparative mechanisms of mesenchymal stem cells for retinal diseases. International Journal of Molecular Sciences 18. https://doi.org/10.3390/ ijms 18081406

3. Gater R (2016) Development of Better Treatments for Retinal Disease Using Stem Cell Therapies. International Journal of Stem cell Research \& Therapy. https://doi.org/10.23937/2469$570 \mathrm{x} / 1410032$

4. Sergejeva, O., Botov, R., Liutkeviciene, R., \& Kriauciuniene, L. (2016). Genetic factors associated with the development of agerelated macular degeneration. Medicina-Lithuania, 52(2), 79-88. https://doi.org/10.1016/j.medici.2016.02.004.

5. Campagne, M. V., LeCouter, J., Yaspan, B. L., \& Ye, W. L. (2014). Mechanisms of age-related macular degeneration and 
therapeutic opportunities. Journal of Pathology, 232(2), 151-164. https://doi.org/10.1002/path.4266.

6. Ramsden CM, Powner MB, Carr A-JF, Smart MJK, da Cruz L, Coffey PJ (2013) Stem cells in retinal regeneration: past, present and future. Development (Cambridge, England). https://doi.org/ 10.1242/dev.092270

7. Nasonkin, I., Illing, M., Koehler, M. R., Schmid, M., Molday, R. S., \& Weber, B. H. F. (1998). Mapping of the rod photoreceptor $\mathrm{ABC}$ transporter $(\mathrm{ABCR})$ to 1p21-p22.1 and identification of novel mutations in Stargardt's disease. Human Genetics, 102(1), 2126. https://doi.org/10.1007/s004390050649.

8. Mata NL, Weng J, Travis GH (2000) Biosynthesis of a major lipofuscin fluorophore in mice and humans with ABCRmediated retinal and macular degeneration. Proceedings of the National Academy of Sciences of the United States of America. https://doi.org/10.1073/pnas.130110497

9. Molday, L. L., Rabin, A. R., \& Molday, R. S. (2000). ABCR expression in foveal cone photoreceptors and its role in Stargardt macular dystrophy. Nature Genetics, 25(3), 257-258.

10. Eandi, C. M., Alovisi, C., De Sanctis, U., \& Grignolo, F. M. (2016). Treatment for neovascularage related macular degeneration: The state of the art. European Journal of Pharmacology, 787, 78-83. https://doi.org/10.1016/j.ejphar.2016.03.002.

11. Singh, S. R., Fung, A. T., Fraser-Bell, S., Lupidi, M., Mohan, S., Gabrielle, P. H., Zur, D., Iglicki, M., Lopez-Corell, P. M., Gallego-Pinazo, R., Farinha, C., Lima, L. H., Mansour, A. M., Casella, A. M., Wu, L. T., Silva, R., Uwaydat, S. H., Govindahari, V., Arevalo, J. F., \& Chhablani, J. (2020). Oneyear outcomes of anti-vascular endothelial growth factor therapy in peripapillary choroidal neovascularisation. British Journal of Ophthalmology, 104(5), 678-683. https://doi.org/10.1136/ bjophthalmol-2019-314542.

12. Boye SE, Boye SL, Lewin AS, Hauswirth WW (2013) A comprehensive review of retinal gene therapy. Molecular Therapy. https:// doi.org/10.1038/mt.2012.280

13. Lai CM, Estcourt MJ, Wikstrom M, Himbeck RP, Barnett NL, Brankov M, Tee LBG, Dunlop SA, Degli-Esposti MA, Rakoczy EP (2009) rAAV.sFlt-1 gene therapy achieves lasting reversal of retinal neovascularization in the absence of a strong immune response to the viral vector. Investigative Ophthalmology and Visual Science. https://doi.org/10.1167/iovs.08-3253

14. Heier JS, Kherani S, Desai S, Dugel P, Kaushal S, Cheng SH, Delacono C, Purvis A, Richards S, Le-Halpere A, Connelly J, Wadsworth SC, Varona R, Buggage R, Scaria A, Campochiaro PA (2017) Intravitreous injection of AAV2-sFLT01 in patients with advanced neovascular age-related macular degeneration: a phase 1, open-label trial. The Lancet. https://doi.org/10.1016/ S0140-6736(17)30979-0

15. MacLachlan TK, Lukason M, Collins M, Munger R, Isenberger E, Rogers C, Malatos S, Dufresne E, Morris J, Calcedo R, Veres G, Scaria A, Andrews L, Wadsworth S (2011) Preclinical safety evaluation of AAV2-sFLT01 a gene therapy for age-related macular degeneration. Molecular Therapy. https://doi.org/10.1038/mt. 2010.258

16. Rakoczy EP (2017) Gene therapy for the long term treatment of wet AMD. The Lancet. https://doi.org/10.1016/S0140-6736(17) 31262-X

17. Rakoczy EP, Lai CM, Magno AL, Wikstrom ME, French MA, Pierce CM, Schwartz SD, Blumenkranz MS, Chalberg TW, Degli-Esposti MA, Constable IJ (2015) Gene therapy with recombinant adeno-associated vectors for neovascular age-related macular degeneration: 1 year follow-up of a phase 1 randomised clinical trial. The Lancet. https://doi.org/10.1016/S0140-6736(15) 00345-1

18. Riemann CD, Banin E, Barak A, Boyer DS, Ehrlich R, Jaouni T, McDonald R, Telander D, Keane M, Ackert J, Ferguson MD,
Ben-Shabat A, Mones J, Angelini D, Hogge GS, Reubinoff B (2020) Phase I/IIa Clinical Trial of Human Embryonic Stem Cell (hESC)-Derived Retinal Pigmented Epithelium (RPE, OpRegen) Transplantation in Advanced Dry Form Age-Related Macular Degeneration (AMD): Interim Results. Invest Ophth Vis Sci 61 (7)

19. Song, W. K., Park, K. M., Kim, H. J., Lee, J. H., Choi, J., Chong, S. Y., et al. (2015). Treatment of macular degeneration using embryonic stem cell-derived retinal pigment epithelium: preliminary results in Asian patients. Stem cell reports, 4(5), 860-872. https:// doi.org/10.1016/j.stemcr.2015.04.005.

20. Schwartz SD, Regillo CD, Lam BL, Eliott D, Rosenfeld PJ, Gregori NZ, Hubschman JP, Davis JL, Heilwell G, Spirn M, Maguire J, Gay R, Bateman J, Ostrick RM, Morris D, Vincent M, Anglade E, Del Priore LV, Lanza R (2015) Human embryonic stem cell-derived retinal pigment epithelium in patients with agerelated macular degeneration and Stargardt's macular dystrophy: Follow-up of two open-label phase 1/2 studies. The Lancet. https://doi.org/10.1016/S0140-6736(14)61376-3

21. Bracha P, Moore NA, Ciulla TA (2017) Induced pluripotent stem cell-based therapy for age-related macular degeneration. Expert Opinion on Biological Therapy. https://doi.org/10.1080/ 14712598.2017.1346079

22. Mandai M, Watanabe A, Kurimoto Y, Hirami Y, Morinaga C, Daimon T, Fujihara M, Akimaru H, Sakai N, Shibata Y, Terada M, Nomiya Y, Tanishima S, Nakamura M, Kamao H, Sugita S, Onishi A, Ito T, Fujita K, Kawamata S, Go MJ, Shinohara C, Hata K, Sawada M, Yamamoto M, Ohta S, Ohara Y, Yoshida K, Kuwahara J, Kitano Y, Amano N, Umekage M, Kitaoka F, Tanaka A, Okada C, Takasu N, Ogawa S, Yamanaka S, Takahashi M (2017) Autologous induced stem-cell-derived retinal cells for macular degeneration. New England Journal of Medicine. https://doi.org/10.1056/NEJMoa1608368

23. Tsang, S. H., \& Sharma, T. (2018). Retinitis Pigmentosa (Nonsyndromic). Atlas of Inherited Retinal Diseases, 1085, 125-130. https://doi.org/10.1007/978-3-319-95046-4_25.

24. Tsang, S. H., \& Sharma, T. (2018). Autosomal Dominant Retinitis Pigmentosa. Atlas of Inherited Retinal Diseases, 1085, 69-77. https://doi.org/10.1007/978-3-319-95046-4_15.

25. Tsang, S. H., \& Sharma, T. (2018). X-linked Retinitis Pigmentosa. Atlas of Inherited Retinal Diseases, 1085, 31-35. https://doi.org/ 10.1007/978-3-319-95046-4 8.

26. Bhattacharya, S. S., \& Chakarova, C. F. (2013). Retinitis Pigmentosa. Brenner's Encyclopedia of Genetics: Second Edition. https://doi.org/10.1016/B978-0-12-374984-0.01318-8.

27. Ran, X., Cai, W. J., Huang, X. F., Liu, Q., Lu, F., Qu, J., Wu, J., \& Jin, Z. B. (2014). 'RetinoGenetics': A comprehensive mutation database for genes related to inherited retinal degeneration. Database. https://doi.org/10.1093/database/bau047.

28. Wert, K. J., Lin, J. H., \& Tsang, S. H. (2014). General pathophysiology in retinal degeneration. Cell-Based Therapy for Retinal Degenerative Disease. https://doi.org/10.1159/000357294.

29. Daiger, S. P., Sullivan, L. S., \& Bowne, S. J. (2013). Genes and mutations causing retinitis pigmentosa. Clinical Genetics. https:// doi.org/10.1111/cge.12203.

30. Al-Saikhan, F. I. (2013). The gene therapy revolution in ophthalmology. Saudi Journal of Ophthalmology. https://doi.org/10. 1016/j.sjopt.2013.02.001.

31. Al-khersan, H., Shah, K. P., Jung, S. C., Rodriguez, A., Madduri, R. K., \& Grassi, M. A. (2017). A novel MERTK mutation causing retinitis pigmentosa. Graefe's Archive for Clinical and Experimental Ophthalmology. https://doi.org/10.1007/s00417017-3679-9.

32. Conlon, T. J., Deng, W. T., Erger, K., Cossette, T., Pang, J. J., Ryals, R., Clement, N., Cleaver, B., McDoom, I., Boye, S. E., Peden, M. C., Sherwood, M. B., Abernathy, C. R., Alkuraya, F. 
S., Boye, S. L., \& Hauswirth, W. W. (2013). Preclinical Potency and Safety Studies of an AAV2-Mediated Gene Therapy Vector for the Treatment of MERTK Associated Retinitis Pigmentosa. Human Gene Therapy Clinical Development, 24(1), 23-28. https://doi.org/10.1089/humc.2013.037.

33. Ghazi, N. G., Abboud, E. B., Nowilaty, S. R., Alkuraya, H., Alhommadi, A., Cai, H. M., Hou, R., Deng, W. T., Boye, S. L., Almaghamsi, A., Al Saikhan, F., Al-Dhibi, H., Birch, D., Chung, C., Colak, D., LaVail, M. M., Vollrath, D., Erger, K., Wang, W. Q., Conlon, T., Zhang, K., Hauswirth, W., \& Alkuraya, F. S. (2016). Treatment of retinitis pigmentosa due to MERTK mutations by ocular subretinal injection of adeno-associated virus gene vector: results of a phase I trial. Human Genetics, 135(3), 327343. https://doi.org/10.1007/s00439-016-1637-y.

34. Fischer, M. D., McClements, M. E., Martinez-Fernandez de la Camara, C., Bellingrath, J. S., Dauletbekov, D., Ramsden, S. C., Hickey, D. G., Barnard, A. R., \& MacLaren, R. E. (2017). CodonOptimized RPGR Improves Stability and Efficacy of AAV8 Gene Therapy in Two Mouse Models of X-Linked Retinitis Pigmentosa. Molecular Therapy. https://doi.org/10.1016/j.ymthe. 2017.05.005.

35. Agency EM (2019) Luxturna (voretigene neparvovec) | EMA. 2019-01-11

36. Da Cruz, L., Coley, B. F., Dorn, J., Merlini, F., Filley, E., Christopher, P., Chen, F. K., Wuyyuru, V., Sahel, J., Stanga, P., Humayun, M., Greenberg, R. J., \& Dagnelie, G. (2013). The Argus II epiretinal prosthesis system allows letter and word reading and long-term function in patients with profound vision loss. British Journal of Ophthalmology. https://doi.org/10.1136/ bjophthalmol-2012-301525.

37. da Cruz, L., Dorn, J. D., Humayun, M. S., Dagnelie, G., Handa, J., Barale, P. O., Sahel, J. A., Stanga, P. E., Hafezi, F., Safran, A. B., Salzmann, J., Santos, A., Birch, D., Spencer, R., Cideciyan, A. V., de Juan, E., Duncan, J. L., Eliott, D., Fawzi, A., Olmos de Koo, L. C., Ho, A. C., Brown, G., Haller, J., Regillo, C., Del Priore, L. V., Arditi, A., \& Greenberg, R. J. (2016). Five-Year Safety and Performance Results from the Argus II Retinal Prosthesis System Clinical Trial. Ophthalmology. https://doi.org/10.1016/j. ophtha.2016.06.049.

38. Burnight, E. R., Gupta, M., Wiley, L. A., Anfinson, K. R., Tran, A., Triboulet, R., Hoffmann, J. M., Klaahsen, D. L., Andorf, J. L., Jiao, C., Sohn, E. H., Adur, M. K., Ross, J. W., Mullins, R. F., Daley, G. Q., Schlaeger, T. M., Stone, E. M., \& Tucker, B. A. (2017). Using CRISPR-Cas9 to Generate Gene-Corrected Autologous iPSCs for the Treatment of Inherited Retinal Degeneration. Molecular Therapy. https://doi.org/10.1016/j. ymthe.2017.05.015.

39. Deng, W. L., Gao, M. L., Lei, X. L., Lv, J. N., Zhao, H., He, K. W., Xia, X. X., Li, L. Y., Chen, Y. C., Li, Y. P., Pan, D., Xue, T., \& Jin, Z. B. (2018). Gene Correction Reverses Ciliopathy and Photoreceptor Loss in iPSC-Derived Retinal Organoids from Retinitis Pigmentosa Patients (vol 10,pg 1267, 2018). Stem Cell Reports, 10(6), 2005-2005. https://doi.org/10.1016/j.stemcr.2018. 05.012 .

40. Gupta, N., \& Gupta, R. (2015). Diabetic Retinopathy - An Update. Journal International Medical Sciences Academy.

41. Kowluru, R. A., \& Mishra, M. (2015). Oxidative stress, mitochondrial damage and diabetic retinopathy. Biochimica Et Biophysica Acta-Molecular Basis of Disease, 1852(11), 2474-2483. https:// doi.org/10.1016/j.bbadis.2015.08.001.

42. Abcouwer, S. F., \& Gardner, T. W. (2014). Diabetic retinopathy: Loss of neuroretinal adaptation to the diabetic metabolic environment. Annals of the New York Academy of Sciences. https://doi. org/10.1111/nyas.12412.

43. Vujosevic, S., \& Simó, R. (2017). Local and systemic inflammatory biomarkers of diabetic retinopathy: An integrative approach.
Investigative Ophthalmology and Visual Science. https://doi.org/ 10.1167/iovs.17-21769.

44. Krick, T. W., \& Bressler, N. M. (2018). Recent clinically relevant highlights from the Diabetic Retinopathy Clinical Research Network. Current Opinion in Ophthalmology. https://doi.org/10. 1097/ICU.0000000000000472.

45. Diaz-Lezama, N., Wu, Z. J., Adan-Castro, E., Arnold, E., Vazquez-Membrillo, M., Arredondo-Zamarripa, D., LedesmaColunga, M. G., Moreno-Carranza, B., de la Escalera, G. M., Colosi, P., \& Clapp, C. (2016). Diabetes enhances the efficacy of AAV2 vectors in the retina: therapeutic effect of AAV2 encoding vasoinhibin and soluble VEGF receptor 1. Laboratory Investigation, 96(3), 283-295. https://doi.org/10.1038/labinvest. 2015.135 .

46. Zhang, X., Das, S. K., Passi, S. F., Uehara, H., Bohner, A., Chen, M., Tiem, M., Archer, B., \& Ambati, B. K. (2015). AAV2 delivery of Flt23k intraceptors inhibits murine choroidal neovascularization. Molecular Therapy. https://doi.org/10.1038/mt.2014.199.

47. Biswal, M. R., Prentice, H. M., Dorey, C. K., \& Blanks, J. C. (2014). A hypoxia-responsive glial cell-specific gene therapy vector for targeting retinal neovascularization. Investigative Ophthalmology and Visual Science. https://doi.org/10.1167/iovs. 14-13932.

48. Tu, L., Wang, J. H., Barathi, V. A., Prea, S. M., He, Z., Lee, J. H., Bender, J., King, A. E., Logan, G. J., Alexander, I. E., Bee, Y. S., Tai, M. H., Dusting, G. J., Bui, B. V., Zhong, J., \& Liu, G. S. (2018). AAV-mediated gene delivery of the calreticulin antiangiogenic domain inhibits ocular neovascularization. Angiogenesis. https://doi.org/10.1007/s10456-017-9591-4.

49. Garcia-Garcia, L., Recalde, S., Hernandez, M., Bezunartea, J., Rodriguez-Madoz, J. R., Johnen, S., Diarra, S., Marie, C., Izsvák, Z., Ivics, Z., Scherman, D., Kropp, M., Thumann, G., Prosper, F., Fernandez-Robredo, P., \& Garcia-Layana, A. (2017). Long-Term PEDF Release in Rat Iris and Retinal Epithelial Cells after Sleeping Beauty Transposon-Mediated Gene Delivery. Molecular Therapy - Nucleic Acids. https://doi. org/10.1016/j.omtn.2017.08.001.

50. Xu, H., Zhang, L. M., Gu, L. M., Lu, L. X., Gao, G. P., Li, W. Y., Xu, G. X., Wang, J., Gao, F. R., Xu, J. Y., Yao, J., Wang, F., Zhang, J. F., \& Xu, G. T. (2014). Subretinal Delivery of AAV2Mediated Human Erythropoietin Gene Is Protective and Safe in Experimental Diabetic Retinopathy. Invest Ophth Vis Sci, 55(3), 1519-1530. https://doi.org/10.1167/iovs.13-13155.

51. Adhi, M., Cashman, S. M., \& Kumar-Singh, R. (2013). AdenoAssociated Virus Mediated Delivery of a Non-Membrane Targeted Human Soluble CD59 Attenuates Some Aspects of Diabetic Retinopathy in Mice. Plos One, 8(10), ARTN e79661. https://doi.org/10.1371/journal.pone.0079661.

52. Zhang, L., Xia, H., Han, Q., \& Chen, B. (2014). Effects of antioxidant gene therapy on the development of diabetic retinopathy and the metabolic memory phenomenon. Graefe's Archive for Clinical and Experimental Ophthalmology. https://doi.org/10. 1007/s00417-014-2827-8.

53. Dominguez, J. M., Hu, P., Caballero, S., Moldovan, L., Verma, A., Oudit, G. Y., Li, Q. H., \& Grant, M. B. (2016). AdenoAssociated Virus Overexpression of Angiotensin-Converting Enzyme-2 Reverses Diabetic Retinopathy in Type 1 Diabetes in Mice. American Journal of Pathology, 186(6), 1688-1700. https://doi.org/10.1016/j.ajpath.2016.01.023.

54. Evangelho, K., Mogilevskaya, M., Losada-Barragan, M., \& Vargas-Sanchez, J. K. (2019). Pathophysiology of primary open-angle glaucoma from a neuroinflammatory and neurotoxicity perspective: a review of the literature. International Ophthalmology, 39(1), 259-271. https://doi.org/10.1007/ s10792-017-0795-9. 
55. Weinreb, R. N., Aung, T., \& Medeiros, F. A. (2014). The pathophysiology and treatment of glaucoma: A review. JAMA - Journal of the American Medical Association. https://doi.org/10.1001/ jama.2014.3192.

56. Conlon, R., Saheb, H., \& Ahmed, I. I. K. (2017). Glaucoma treatment trends: a review. Canadian Journal of OphthalmologyJournal Canadien D Ophtalmologie, 52(1), 114-124. https://doi. org/10.1016/j.jcjo.2016.07.013.

57. Avar, M., Jordan, J. F., Neuburger, M., Engesser, D., Lubke, J., Anton, A., \& Wecker, T. (2019). Long-term follow-up of intraocular pressure and pressure-lowering medication in patients after ab-interno trabeculectomy with the Trabectome. Graefes Archive for Clinical and Experimental Ophthalmology, 257(5), 997-1003. https://doi.org/10.1007/s00417-019-04259-5.

58. Khawaja, A. P., JNC, B., Wareham, N. J., Scott, R. A., Simcoe, M., Igo, R. P., Song, Y. E., Wojciechowski, R., Cheng, C. Y., Khaw, P. T., Pasquale, L. R., Haines, J. L., Foster, P. J., Wiggs, J. L., Hammond, C. J., Hysi, P. G., UBEV, C., \& Consortium, N. (2018). Genome-wide analyses identify 68 new loci associated with intraocular pressure and improve risk prediction for primary open-angle glaucoma. Nature Genetics, 50(6), 778. https://doi. org/10.1038/s41588-018-0126-8.

59. Khatib, T. Z., \& Martin, K. R. (2020). Neuroprotection in Glaucoma: Towards Clinical Trials and Precision Medicine. Current Eye Research, 45(3), 327-338. https://doi.org/10.1080/ 02713683.2019.1663385.

60. Osborne, A., Wang, A. X. Z., Tassoni, A., Widdowson, P. S., \& Martin, K. R. (2018). Design of a Novel Gene Therapy Construct to Achieve Sustained Brain-Derived Neurotrophic Factor Signaling in Neurons. Human Gene Therapy, 29(7), 828-841. https://doi.org/10.1089/hum.2017.069.

61. Osborne A, Khatib TZ, Songra L, Barber AC, Hall K, Kong GYX, Widdowson PS, Martin KR (2018) Neuroprotection of retinal ganglion cells by a novel gene therapy construct that achieves sustained enhancement of brain-derived neurotrophic factor/ tropomyosin- related kinase receptor-B signaling. Cell Death \& Disease 9. ARTN 1007. https://doi.org/10.1038/s41419-0181041-8

62. Wu, J. H., Bell, O. H., Copland, D. A., Young, A., Pooley, J. R., Maswood, R., Evans, R. S., Khaw, P. T., Ali, R. R., Dick, A. D., \& Chu, C. J. (2020). Gene Therapy for Glaucoma by Ciliary Body Aquaporin 1 Disruption Using CRISPR-Cas9. Molecular Therapy, 28(3), 820-829. https://doi.org/10.1016/j.ymthe.2019. 12.012 .

63. Mead, B., Berry, M., Logan, A., Scott, R. A. H., Leadbeater, W., \& Scheven, B. A. (2015). Stem cell treatment of degenerative eye disease. Stem Cell Research, 14, 243-257. https://doi.org/10. 1016/j.scr.2015.02.003.

64. Usategui-Martín, R., Puertas-Neyra, K., García-Gutiérrez, M. T., Fuentes, M., Pastor, J. C., \& Fernandez-Bueno, I. (2020). Human Mesenchymal Stem Cell Secretome Exhibits a Neuroprotective Effect over In Vitro Retinal Photoreceptor Degeneration. Molecular Therapy - Methods and Clinical Development. https:// doi.org/10.1016/j.omtm.2020.05.003.

65. Salehi, H., Amirpour, N., Razavi, S., Esfandiari, E., \& Zavar, R. (2017). Overview of retinal differentiation potential of mesenchymal stem cells: A promising approach for retinal cell therapy. Annals of Anatomy, 210, 52-63. https://doi.org/10.1016/j.aanat. 2016.11.010.

66. Konala, V. B. R., Mamidi, M. K., Bhonde, R., Das, A. K., Pochampally, R., \& Pal, R. (2016). The current landscape of the mesenchymal stromal cell secretome: A new paradigm for cellfree regeneration. Cytotherapy. https://doi.org/10.1016/j.jcyt. 2015.10.008.

67. Osborne, A., Sanderson, J., \& Martin, K. R. (2018). Neuroprotective Effects of Human Mesenchymal Stem Cells and Platelet-Derived Growth Factor on Human Retinal Ganglion Cells. Stem Cells. https://doi.org/10.1002/stem.2722.

68. Cui, Y., Xu, N., Xu, W., \& Xu, G. (2016). Mesenchymal stem cells attenuate hydrogen peroxide-induced oxidative stress and enhance neuroprotective effects in retinal ganglion cells. In Vitro Cellular and Developmental Biology - Animal, 53, 328-335. https://doi.org/10.1007/s11626-016-0115-0.

69. Johnson, T. V., Dekorver, N. W., Levasseur, V. A., Osborne, A., Tassoni, A., Lorber, B., Heller, J. P., Villasmil, R., Bull, N. D., Martin, K. R., \& Tomarev, S. I. (2014). Identification of retinal ganglion cell neuroprotection conferred by platelet-derived growth factor through analysis of the mesenchymal stem cell secretome. Brain, 137, 503-519. https://doi.org/10.1093/brain/ awt292.

70. Mead, B., Logan, A., Berry, M., Leadbeater, W., \& Scheven, B. A. (2013). Intravitreally transplanted dental pulp stem cells promote neuroprotection and axon regeneration of retinal ganglion cells after optic nerve injury. Investigative Ophthalmology and Visual Science. https://doi.org/10.1167/iovs.13-13045.

71. Mead, B., Logan, A., Berry, M., Leadbeater, W., \& Scheven, B. A. (2014). Paracrine-mediated neuroprotection and neuritogenesis of axotomised retinal ganglion cells by human dental pulp stem cells: Comparison with human bone marrow and adipose-derived mesenchymal stem cells. PLoS ONE, 9. https://doi.org/10.1371/journal.pone.0109305.

72. Hu, Z. L., Li, N., Wei, X., Tang, L., Wang, T. H., \& Chen, X. M. (2017). Neuroprotective effects of BDNF and GDNF in intravitreally transplanted mesenchymal stem cells after optic nerve crush in mice. International Journal of Ophthalmology, 10(1), 35-42. https://doi.org/10.18240/ijo.2017.01.06.

73. Mesentier-Louro, L. A., Zaverucha-do-Valle, C., da Silva, A. J., Nascimento-dos-Santos, G., Gubert, F., de Figueiredo, A. B. P., Torres, A. L., Paredes, B. D., Teixeira, C., Tovar-Moll, F., Mendez-Otero, R., \& Santiago, M. F. (2014). Distribution of Mesenchymal Stem Cells and Effects on Neuronal Survival and Axon Regeneration after Optic Nerve Crush and Cell Therapy. Plos One, 9(10), ARTN e110722. https://doi.org/10.1371/ journal.pone.0110722.

74. Fontanilla CV, Gu HY, Liu QP, Zhu TZ, Zhou CW, Johnstone BH, March KL, Pascuzzi RM, Farlow MR, Du YS (2016) Adipose-derived Stem Cell Conditioned Media Extends Survival time of a mouse model of Amyotrophic Lateral Sclerosis (vol 5, 16953, 2015). Scientific Reports 6. ARTN 20747 https://doi.org/ $10.1038 /$ srep20747

75. Noverina, R., Widowati, W., Ayuningtyas, W., Kurniawan, D., Afifah, E., Laksmitawati, D. R., Rinendyaputri, R., Rilianawati, R., Faried, A., Bachtiar, I., \& Wirakusumah, F. F. (2019). Growth factors profile in conditioned medium human adipose tissuederived mesenchymal stem cells (CM-hATMSCs). Clinical Nutrition Experimental. https://doi.org/10.1016/j.yclnex.2019.01. 002.

76. Mead, B., Logan, A., Berry, M., Leadbeater, W., \& Scheven, B. A. (2014). Paracrine-Mediated Neuroprotection and Neuritogenesis of Axotomised Retinal Ganglion Cells by Human Dental Pulp Stem Cells: Comparison with Human Bone Marrow and Adipose-Derived Mesenchymal Stem Cells. Plos One, $(9,10)$, ARTN e109305. https://doi.org/10.1371/journal. pone. 0109305 .

77. Ezquer, M., Urzua, C. A., Montecino, S., Leal, K., Conget, P., \& Ezquer, F. (2016). Intravitreal administration of multipotent mesenchymal stromal cells triggers a cytoprotective microenvironment in the retina of diabetic mice. Stem Cell Research and Therapy, 7, 1-17. https://doi.org/10.1186/s13287-016-0299-y.

78. Barzelay A, Algor SW, Niztan A, Katz S, Benhamou M, Nakdimon I, Azmon N, Gozlan S, Mezad-Koursh D, Neudorfer M, Goldstein M, Meilik B, Loewenstein A, Barak A (2018) 
Adipose-Derived Mesenchymal Stem Cells Migrate and Rescue RPE in the Setting of Oxidative Stress. Stem Cells International 2018. Artn 9682856 https://doi.org/10.1155/2018/9682856

79. Sugitani, S., Tsuruma, K., Ohno, Y., Kuse, Y., Yamauchi, M., Egashira, Y., Yoshimura, S., Shimazawa, M., Iwama, T., \& Hara, H. (2013). The potential neuroprotective effect of human adipose stem cells conditioned medium against light-induced retinal damage. Exp Eye Res, 116, 254-264. https://doi.org/10.1016/ j.exer.2013.09.013.

80. Tsuruma, K., Yamauchi, M., Sugitani, S., Otsuka, T., Ohno, Y., Nagahara, Y., Ikegame, Y., Shimazawa, M., Yoshimura, S., Iwama, T., \& Hara, H. (2014). Progranulin, a Major Secreted Protein of Mouse Adipose-Derived Stem Cells, Inhibits LightInduced Retinal Degeneration. STEM CELLS Translational Medicine, 3, 42-53. https://doi.org/10.5966/sctm.2013-0020.

81. Mead, B., Hill, L. J., Blanch, R. J., Ward, K., Logan, A., Berry, M., Leadbeater, W., \& Scheven, B. A. (2016). Mesenchymal stromal cell-mediated neuroprotection and functional preservation of retinal ganglion cells in a rodent model of glaucoma. Cytotherapy, 18, 487-496. https://doi.org/10.1016/j.jcyt.2015.12.002.

82. Ji, S., Lin, S., Chen, J., Huang, X., Wei, C. C., Li, Z., \& Tang, S. (2018). Neuroprotection of Transplanting Human Umbilical Cord Mesenchymal Stem Cells in a Microbead Induced Ocular Hypertension Rat Model. Current Eye Research. https://doi.org/ 10.1080/02713683.2018.1440604.

83. Zhang W, Wang YX, Kong JH, Dong M, Duan HT, Chen S (2017) Therapeutic efficacy of neural stem cells originating from umbilical cord-derived mesenchymal stem cells in diabetic retinopathy. Scientific Reports 7. ARTN 408 https://doi.org/10.1038/ s41598-017-00298-2

84. Millan-Rivero JE, Nadal-Nicolas FM, Garcia-Bernal D, SobradoCalvo P, Blanquer M, Moraleda JM, Vidal-Sanz M, AgudoBarriuso M (2018) Human Wharton's jelly mesenchymal stem cells protect axotomized rat retinal ganglion cells via secretion of anti-inflammatory and neurotrophic factors. Scientific Reports 8 . ARTN 16299 https://doi.org/10.1038/s41598-018-34527-z

85. Mathew, B., Ravindran, S., Liu, X., Torres, L., Chennakesavalu, M., Huang, C. C., Feng, L., Zelka, R., Lopez, J., Sharma, M., \& Roth, S. (2019). Mesenchymal stem cell-derived extracellular vesicles and retinal ischemia-reperfusion. Biomaterials. https://doi. org/10.1016/j.biomaterials.2019.01.016.

86. Yu, B., Shao, H., Su, C., Jiang, Y., Chen, X., Bai, L., Zhang, Y., Li, Q., Zhang, X., \& Li, X. (2016). Exosomes derived from MSCs ameliorate retinal laser injury partially by inhibition of MCP-1. Scientific Reports, 6, 1-12. https://doi.org/10.1038/srep34562.

87. He, G. H., Zhang, W., Ma, Y. X., Yang, J., Chen, L., Song, J., \& Chen, S. (2018). Mesenchymal stem cells-derived exosomes ameliorate blue light stimulation in retinal pigment epithelium cells and retinal laser injury by VEGF-dependent mechanism. International Journal of Ophthalmology, 11, 559-566. https:// doi.org/10.18240/ijo.2018.04.04.

88. Mead, B., \& Tomarev, S. (2017). Bone marrow-derived mesenchymal stem cells-derived exosomes promote survival of retinal ganglion cells through mirna-dependent mechanisms. Stem Cells Translational Medicine. https://doi.org/10.1002/sctm.16-0428.

89. Mead, B., Ahmed, Z., \& Tomarev, S. (2018). Mesenchymal stem cell-Derived small extracellular vesicles promote neuroprotection in a genetic DBA/2J mouse model of glaucoma. Investigative Ophthalmology and Visual Science. https://doi.org/10.1167/iovs. 18-25310.

90. Mead, B., Amaral, J., \& Tomarev, S. (2018). Mesenchymal Stem Cell-Derived Small Extracellular Vesicles Promote Neuroprotection in Rodent Models of Glaucoma. Invest Ophth Vis Sci, 59(2), 702-714. https://doi.org/10.1167/iovs.17-22855.

91. Safwat, A., Sabry, D., Ragiae, A., Amer, E., Mahmoud, R. H., \& Shamardan, R. M. (2018). Adipose mesenchymal stem cells- derived exosomes attenuate retina degeneration of streptozotocin-induced diabetes in rabbits. Journal of Circulating Biomarkers, 7, 1-10. https://doi.org/10.1177/ 1849454418807827

92. Taylor AW (2016) Ocular Immune Privilege and Transplantation. Frontiers in Immunology 7. ARTN 37 https://doi.org/10.3389/ fimmu.2016.00037

93. Keino H, Horie S, Sugita S (2018) Immune Privilege and EyeDerived T-Regulatory Cells. Journal of Immunology Research 2018. Artn 1679197 https://doi.org/10.1155/2018/1679197

94. Taylor, A. W., \& Ng, T. F. (2018). Negative regulators that mediate ocular immune privilege. Journal of Leukocyte Biology, 103(6), 1179-1187. https://doi.org/10.1002/Jlb.3mir0817-337r.

95. Forrester, J. V., \& Xu, H. (2012). Good news-bad news: The Yin and Yang of immune privilege in the eye. Frontiers in Immunology, 3, 1-18. https://doi.org/10.3389/fimmu.2012. 00338.

96. Perez, V. L., \& Caspi, R. R. (2015). Immune mechanisms in inflammatory and degenerative eye disease. Trends in Immunology. https://doi.org/10.1016/j.it.2015.04.003.

97. Nussenblatt, R. B., Lee, R. W. J., Chew, E., Wei, L., Liu, B. Y., Sen, H. N., Dick, A. D., \& Ferris, F. L. (2014). Immune Responses in Age-Related Macular Degeneration and a Possible Long-term Therapeutic Strategy for Prevention. American Journal of Ophthalmology, 158(1), 5-11. https://doi.org/10.1016/j.ajo.2014. 03.014 .

98. Soto, I., \& Howell, G. R. (2014). The complex role of neuroinflammation in glaucoma. Cold Spring Harbor Perspectives in Medicine, 4, 14. https://doi.org/10.1101/cshperspect.a017269.

99. Rubsam, A., Parikh, S., \& Fort, P. E. (2018). Role of Inflammation in Diabetic Retinopathy. International Journal of Molecular Sciences 19 (4). ARTN 942. https://doi.org/10.3390/ ijms19040942.

100. Wang, M., Yuan, Q., \& Xie, L. (2018). Review Article Mesenchymal Stem Cell-Based Immunomodulation. Properties and Clinical Application, 2018, 101.

101. de Castro, L. L., Lopes-Pacheco, M., Weiss, D. J., Cruz, F. F., \& Rocco, P. R. M. (2019). Current understanding of the immunosuppressive properties of mesenchymal stromal cells. Journal of Molecular Medicine-Jmm, 97(5), 605-618. https://doi.org/10. 1007/s00109-019-01776-y.

102. Wang, M., Yuan, Q., \& Xie, L. (2018). Mesenchymal stem cellbased immunomodulation: Properties and clinical application. Stem Cells International. https://doi.org/10.1155/2018/3057624.

103. Dostert, G., Mesure, B., Menu, P., \& Velot, É. (2017). How Do Mesenchymal Stem Cells Influence or Are Influenced by Microenvironment through Extracellular Vesicles Communication? Frontiers in Cell and Developmental Biology. https://doi.org/10.3389/fcell.2017.00006.

104. Zhang, B., Yin, Y., Lai, R. C., Tan, S. S., Choo, A. B. H., \& Lim, S. K. (2014). Mesenchymal stem cells secrete immunologically active exosomes. Stem Cells and Development. https://doi.org/ 10.1089/scd.2013.0479.

105. Hermankova, B., Kossl, J., Bohacova, P., Javorkova, E., Hajkova, M., Krulova, M., Zajicova, A., \& Holan, V. (2019). The Immunomodulatory Potential of Mesenchymal Stem Cells in a Retinal Inflammatory Environment. Stem Cell Reviews and Reports. https://doi.org/10.1007/s12015-019-09908-0.

106. Lee, M. J., Ko, A. Y., Ko, J. H., Lee, H. J., Kim, M. K., Wee, W. R., Khwarg, S. I., \& Oh, J. Y. (2015). Mesenchymal stem/stromal cells protect the ocular surface by suppressing inflammation in an experimental dry eye. Molecular Therapy, 23, 139-146. https:// doi.org/10.1038/mt.2014.159.

107. Holan, V., Hermankova, B., \& Kossl, J. (2017). Perspectives of Stem Cell-Based Therapy for Age-Related Retinal Degenerative 
Diseases. Cell Transplantation, 26, 1538-1541. https://doi.org/10. 1177/0963689717721227.

108. Zhang, L., Zheng, H., Shao, H., Nian, H., Zhang, Y., Bai, L., Su, C., Liu, X., Dong, L., Li, X., \& Zhang, X. (2014). Long-term therapeutic effects of mesenchymal stem cells compared to dexamethasone on recurrent experimental autoimmune uveitis of rats. Investigative Ophthalmology and Visual Science, 55, 5561-5571. https://doi.org/10.1167/iovs.14-14788.

109. Emre, E., Yüksel, N., Duruksu, G., Pirhan, D., Subași, C., Erman, G., \& Karaöz, E. (2015). Neuroprotective effects of intravitreally transplanted adipose tissue and bone marrow-derived mesenchymal stem cells in an experimental ocular hypertension model. Cytotherapy, 17, 543-559. https://doi.org/10.1016/j.jcyt.2014.12. 005 .

110. Ji SL, Xiao J, Liu J, Tang SB (2019) Human Umbilical Cord Mesenchymal Stem Cells Attenuate Ocular HypertensionInduced Retinal Neuroinflammation via Toll-Like Receptor 4 Pathway. Stem Cells International 2019. Artn 9274585. https:// doi.org/10.1155/2019/9274585

111. Mathew, B., Poston, J. N., Dreixler, J. C., Torres, L., Lopez, J., Zelkha, R., Balyasnikova, I., Lesniak, M. S., \& Roth, S. (2017). Bone-marrow mesenchymal stem-cell administration significantly improves outcome after retinal ischemia in rats. Graefe's Archive for Clinical and Experimental Ophthalmology. https://doi.org/10. 1007/s00417-017-3690-1.

112. Holan, V., Trosan, P., Cejka, C., Javorkova, E., Zajicova, A., Hermankova, B., Chudickova, M., \& Cejkova, J. (2015). A Comparative Study of the Therapeutic Potential of Mesenchymal Stem Cells and Limbal Epithelial Stem Cells for Ocular Surface Reconstruction. Stem Cells Translational Medicine, 4(9), 1052-1063. https://doi.org/10.5966/sctm.20150039.

113. Cejkova, J., Trosan, P., Cejka, C., Lencova, A., Zajicova, A., Javorkova, E., Kubinova, S., Sykova, E., \& Holan, V. (2013). Suppression of alkali-induced oxidative injury in the cornea by mesenchymal stem cells growing on nanofiber scaffolds and transferred onto the damaged corneal surface. Exp Eye Res, 116, 312323. https://doi.org/10.1016/j.exer.2013.10.002.

114. Paulus, Y. M., \& Sodhi, A. (2017). Anti-angiogenic therapy for retinal disease. Handbook of Experimental Pharmacology. https:// doi.org/10.1007/164_2016_78.

115. Kim, K. S., Park, J. M., Kong, T. H., Kim, C., Bae, S. H., Kim, H. W., \& Moon, J. (2016). Retinal angiogenesis effects of TGF- $\beta 1$ and paracrine factors secreted from human placental stem cells in response to a pathological environment. Cell Transplantation, 25, 1145-1157. https://doi.org/10.3727/096368915X688263.

116. Ghazaryan, E., Zhang, Y., He, Y., Liu, X., Li, Y., Xie, J., \& Su, G. (2016). Mesenchymal stem cells in corneal neovascularization: Comparison of different application routes. Molecular Medicine Reports. https://doi.org/10.3892/mmr.2016.5621.

117. Bazzazi, H., Zhang, Y., Jafarnejad, M., Isenberg, J. S., Annex, B. H., \& Popel, A. S. (2018). Computer simulation of TSP1 inhibition of VEGF-Akt-eNOS: An angiogenesis triple threat. Frontiers in Physiology, 9, 1-14. https://doi.org/10.3389/fphys.2018.00644.

118. Kaur, S., Martin-Manso, G., Pendrak, M. L., Garfield, S. H., Isenberg, J. S., \& Roberts, D. D. (2010). Thrombospondin-1 inhibits VEGF receptor-2 signaling by disrupting its association with CD47. Journal of Biological Chemistry, 285, 3892338932. https://doi.org/10.1074/jbc.M110.172304.

119. Chu, L. Y., Ramakrishnan, D. P., \& Silverstein, R. L. (2013). Thrombospondin-1 modulates VEGF signaling via CD36 by recruiting SHP-1 to VEGFR2 complex in microvascular endothelial cells. Blood, 122, 1822-1832. https://doi.org/10.1182/blood2013-01-482315.

120. Ma, Y., Xu, Y., Xiao, Z., Yang, W., Zhang, C., Song, E., Du, Y., \& Li, L. (2006). Reconstruction of Chemically Burned Rat
Corneal Surface by Bone Marrow-Derived Human Mesenchymal Stem Cells. Stem Cells, 24, 315-321. https://doi. org/10.1634/stemcells.2005-0046.

121. Oh, J. Y., Kim, M. K., Shin, M. S., Lee, H. J., Ko, J. H., Wee, W. R., \& Lee, J. H. (2008). The Anti-Inflammatory and AntiAngiogenic Role of Mesenchymal Stem Cells in Corneal Wound Healing Following Chemical Injury. Stem Cells, 26 , 1047-1055. https://doi.org/10.1634/stemcells.2007-0737.

122. Yao L, Li Zr, Su Wr, Li Yp, Lin Ml, Zhang Wx, Liu Y, Wan Q, Liang D (2012) Role of mesenchymal stem cells on cornea wound healing induced by acute alkali burn. PLoS ONE 7. https://doi.org/ 10.1371/journal.pone.0030842

123. Wang, J. D., An, Y., Zhang, J. S., Wan, X. H., Jonas, J. B., Xu, L., \& Zhang, W. (2017). Human bone marrow mesenchymal stem cells for retinal vascular injury. Acta Ophthalmologica, 95(6), E453-E461. https://doi.org/10.1111/aos.13154.

124. Hou, H. Y., Liang, H. L., Wang, Y. S., Zhang, Z. X., Wang, B. R., Shi, Y. Y., Dong, X., \& Cai, Y. (2010). A therapeutic strategy for choroidal neovascularization based on recruitment of mesenchymal stem cells to the sites of lesions. Molecular Therapy, 18, 1837-1845. https://doi.org/10.1038/mt.2010.144.

125. Mansoor, H., Ong, H. S., Riau, A. K., Stanzel, T. P., Mehta, J. S., $\&$ Yam, G. H. F. (2019). Current Trends and Future Perspective of Mesenchymal Stem Cells and Exosomes in Corneal Diseases. International Journal of Molecular Sciences, 20(12), ARTN 2853. https://doi.org/10.3390/ijms20122853.

126. Feng, Y., Zhu, R., Shen, J., Wu, J., Lu, W., Zhang, J., Zhang, J., \& Liu, K. (2019). Human Bone Marrow Mesenchymal Stem Cells Rescue Endothelial Cells Experiencing Chemotherapy Stress by Mitochondrial Transfer Via Tunneling Nanotubes. Stem Cells and Development. https://doi.org/10.1089/scd.2018.0248.

127. Sinclair KA, Yerkovich ST, Hopkins PMA, Chambers DC (2016) Characterization of intercellular communication and mitochondrial donation by mesenchymal stromal cells derived from the human lung. Stem Cell Research \& Therapy 7. ARTN 91. https://doi.org/ 10.1186/s13287-016-0354-8

128. Monsel, A., Zhu, Y. G., Gennai, S., Hao, Q., Hu, S., Rouby, J. J., Rosenzwajg, M., Matthay, M. A., \& Lee, J. W. (2015). Therapeutic effects of human mesenchymal stem cell-derived microvesicles in severe pneumonia in mice. Am J Resp Crit Care. https://doi.org/10.1164/rccm.201410-1765OC.

129. Phinney, D. G., Di Giuseppe, M., Njah, J., Sala, E., Shiva, S., St Croix, C. M., Stolz, D. B., Watkins, S. C., Di, Y. P., Leikauf, G. D., Kolls, J., Riches, D. W. H., Deiuliis, G., Kaminski, N., Boregowda, S. V., McKenna, D. H., \& Ortiz, L. A. (2015). Mesenchymal stem cells use extracellular vesicles to outsource mitophagy and shuttle microRNAs. Nature Communications. https://doi.org/10.1038/ncomms9472.

130. Li, C., Cheung, M. K. H., Han, S., Zhang, Z., Chen, L., Chen, J., Zeng, H., \& Qiu, J. (2019). Mesenchymal stem cells and their mitochondrial transfer: A double-edged sword. Bioscience Reports. https://doi.org/10.1042/BSR20182417.

131. Li, H., Wang, C., He, T., Zhao, T., Yy, C., Shen, Y., Zhang, X., \& Wang, L. (2019). Mitochondrial transfer from bone marrow mesenchymal stem cells to motor neurons in spinal cord injury rats via gap junction. Theranostics. https://doi.org/10.7150/thno.29400.

132. Ahmad, T., Mukherjee, S., Pattnaik, B. R., Kumar, M., Singh, S., Rehman, R., Kumar, M., Jha, A., Wani, M., Mabalirajan, U., Ghosh, B., Sinha Roy, S., \& Agrawal, A. (2013). Miro 1 Knockdown in Stem Cells Inhibits Mitochondrial Donation Mediated Rescue of Bronchial Epithelial Injury. Biophysical Journal. https://doi.org/10.1016/j.bpj.2012.11.3638.

133. Ahmad, T., Mukherjee, S., Pattnaik, B., Kumar, M., Singh, S., Rehman, R., Tiwari, B. K., Jha, K. A., Barhanpurkar, A. P., Wani, M. R., Roy, S. S., Mabalirajan, U., Ghosh, B., \& Agrawal, A. (2014). Miro1 regulates intercellular mitochondrial 
transport \& enhances mesenchymal stem cell rescue efficacy. EMBO Journal. https://doi.org/10.1002/embj.201386030.

134. Jiang, D., Gao, F., Zhang, Y., Wong, D. S. H., Li, Q., Tse, H. F., Xu, G., Yu, Z., \& Lian, Q. (2016). Mitochondrial transfer of mesenchymal stem cells effectively protects corneal epithelial cells from mitochondrial damage. Cell Death and Disease. https://doi. org/10.1038/cddis.2016.358.

135. Pacak, C. A., Preble, J. M., Kondo, H., Seibel, P., Levitsky, S., del Nido, P. J., Cowan, D. B., \& McCully, J. D. (2015). Actindependent mitochondrial internalization in cardiomyocytes: evidence for rescue of mitochondrial function. Biology Open, 4(5), 622-626. https://doi.org/10.1242/bio.201511478.

136. Plotnikov, E. Y., Khryapenkova, T. G., Vasileva, A. K., Marey, M. V., Galkina, S. I., Isaev, N. K., Sheval, E. V., Polyakov, V. Y., Sukhikh, G. T., \& Zorov, D. B. (2008). Cell-to-cell cross-talk between mesenchymal stem cells and cardiomyocytes in co-culture. Journal of Cellular and Molecular Medicine. https://doi.org/ 10.1111/j.1582-4934.2007.00205.x.

137. Babenko, V. A., Silachev, D. N., Popkov, V. A., Zorova, L. D., Pevzner, I. B., Plotnikov, E. Y., Sukhikh, G. T., \& Zorov, D. B. (2018). Mirol enhances mitochondria transfer from multipotent mesenchymal stem cells (MMSC) to neural cells and improves the efficacy of cell recovery. Molecules. https://doi.org/10.3390/ molecules23030687.

138. Boukelmoune, N., Chiu, G. S., Kavelaars, A., \& Heijnen, C. J. (2018). Mitochondrial transfer from mesenchymal stem cells to neural stem cells protects against the neurotoxic effects of cisplatin. Acta neuropathologica communications. https://doi.org/10. 1186/s40478-018-0644-8.

139. Jiang, D., Xiong, G., Feng, H., Zhang, Z., Chen, P., Yan, B., Chen, L., Gandhervin, K., Ma, C., Li, C., Han, S., Zhang, Y., Liao, C., Lee, T. L., Tse, H. F., Fu, Q. L., Chiu, K., \& Lian, Q. (2019). Donation of mitochondria by iPSC-derived mesenchymal stem cells protects retinal ganglion cells against mitochondrial complex I defect-induced degeneration. Theranostics. https://doi.org/10. 7150/thno.29422.

140. Eells, J. T. (2019). Mitochondrial dysfunction in the aging retina. Biology. https://doi.org/10.3390/biology8020031.

141. Ferland-McCollough, D., Slater, S., Richard, J., Reni, C., \& Mangialardi, G. (2017). Pericytes, an overlooked player in vascular pathobiology. Pharmacology \& Therapeutics, 171, 30-42. https://doi.org/10.1016/j.pharmthera.2016.11.008.

142. Trost, A., Bruckner, D., Rivera, F. J., \& Reitsamer, H. A. (2019). Pericytes in the Retina. Pericyte Biology in Different Organs, 1122, 1-26. https://doi.org/10.1007/978-3-030-11093-2_1.

143. Beltramo, E., \& Porta, M. (2013). Pericyte Loss in Diabetic Retinopathy: Mechanisms and Consequences. Current Medicinal Chemistry, 20(26), 3218-3225. https://doi.org/10. 2174/09298673113209990022.

144. Mendel, T. A., Clabough, E. B. D., Kao, D. S., Demidova-Rice, T. N., Durham, J. T., Zotter, B. C., Seaman, S. A., Cronk, S. M., Rakoczy, E. P., Katz, A. J., Herman, I. M., Peirce, S. M., \& Yates, P. A. (2013). Pericytes Derived from Adipose-Derived Stem Cells Protect against Retinal Vasculopathy. Plos One, 8(5), ARTN e65691. https://doi.org/10.1371/journal.pone.0065691.

145. Caplan, A. I. (2017). New MSC: MSCs as Pericytes Are Sentinels and Gatekeepers. Journal of Orthopaedic Research, 35(6), 11511159. https://doi.org/10.1002/jor.23560.

146. Fiori, A., Terlizzi, V., Kremer, H., Gebauer, J., Hammes, H. P., Harmsen, M. C., \& Bieback, K. (2018). Mesenchymal stromal/ stem cells as potential therapy in diabetic retinopathy. Immunobiology, 223(12), 729-743. https://doi.org/10.1016/j. imbio.2018.01.001.

147. Zimmerlin, L., Donnenberg, V. S., Rubin, J. P., \& Donnenberg, A. D. (2013). Mesenchymal Markers on Human Adipose Stem/
Progenitor Cells. Cytometry Part A, 83a(1), 134-140. https://doi. org/10.1002/cyto.a.22227.

148. Meirelles, L. D., Wagatsuma, V. M. D., Malta, T. M., Palma, P. V. B., Araujo, A. G., Panepucci, R. A., Silva, W. A., Kashima, S., \& Covas, D. T. (2016). The gene expression profile of non-cultured, highly purified human adipose tissue pericytes: Transcriptomic evidence that pericytes are stem cells in human adipose tissue. Experimental Cell Research, 349(2), 239-254. https://doi.org/10. 1016/j.yexer.2016.10.017

149. Terlizzi, V., Kolibabka, M., Burgess, J. K., Hammes, H. P., \& Harmsen, M. C. (2018). The Pericytic Phenotype of Adipose Tissue-Derived Stromal Cells Is Promoted by NOTCH2. Stem Cells, 36(2), 240-251. https://doi.org/10.1002/stem.2726.

150. Rajashekhar, G., Ramadan, A., Abburi, C., Callaghan, B., Traktuev, D. O., Evans-Molina, C., Maturi, R., Harris, A., Kern, T. S., \& March, K. L. (2014). Regenerative Therapeutic Potential of Adipose Stromal Cells in Early Stage Diabetic Retinopathy. Plos One, 9(1), ARTN e84671. https://doi.org/10.1371/journal. pone.0084671.

151. Fiori, A., Hammes, H. P., \& Bieback, K. (2020). Adipose-derived mesenchymal stromal cells reverse high glucose-induced reduction of angiogenesis in human retinal microvascular endothelial cells. Cytotherapy, 22(5), 261-275. https://doi.org/10.1016/j.jcyt. 2020.02.005.

152. Hajmousa, G. (2017). Hyperglycemia Induces Bioenergetic Changes in Adipose-Derived Stromal Cells While Their Pericytic Function Is Retained (vol 25, pg 1444, 2016). Stem Cells and Development, 26(16), 1223-1223. https://doi.org/10. 1089/scd.2016.0025.correx.

153. Hajmousa, G., Elorza, A. A., Nies, V. J. M., Jensen, E. L., Nagy, R. A., \& Harmsen, M. C. (2016). Hyperglycemia Induces Bioenergetic Changes in Adipose-Derived Stromal Cells While Their Pericytic Function Is Retained. Stem Cells and Development, 25(19), 1444-1453. https://doi.org/10.1089/scd. 2016.0025 .

154. Hermankova, B., Kossl, J., Javorkova, E., Bohacova, P., Hajkova, M., Zajicova, A., Krulova, M., \& Holan, V. (2017). The Identification of Interferon-gamma as a Key Supportive Factor for Retinal Differentiation of Murine Mesenchymal Stem Cells. Stem Cells and Development, 26(19), 1399-1408. https://doi.org/ $10.1089 / \mathrm{scd} .2017 .0111$

155. Xu, C. L., Lu, H. Y., Li, F. Q., \& Su, G. F. (2020). Protein Expression Profile on Differentiation of Bone Marrow Mesenchymal Stem Cells into Retinal Ganglion-Like Cells. Journal of Computational Biology, 27(8), 1329-1336. https:// doi.org/10.1089/cmb.2019.0024.

156. Duan, P., Xu, H. W., Zeng, Y. X., Wang, Y., \& Yin, Z. Q. (2013). Human Bone Marrow Stromal Cells can Differentiate to a Retinal Pigment Epithelial Phenotype when Co-Cultured with Pig Retinal Pigment Epithelium using a Transwell System. Cellular Physiology and Biochemistry, 31(4-5), 601-613. https://doi.org/ 10.1159/000350080.

157. Kadkhodaeian, H. A., Tiraihi, T., Ahmadieh, H., Ziaei, H., Daftarian, N., \& Taheri, T. (2019). Generation of Retinal Pigmented Epithelium-Like Cells from Pigmented Spheres Differentiated from Bone Marrow Stromal Cell-Derived Neurospheres. Tissue Engineering and Regenerative Medicine, 16(3), 253-263. https://doi.org/10.1007/s13770-019-00183-1.

158. Huang YQ, Ng TK, Chen CB, Huang B, Liang JJ, Pang CP, Zhang MZ (2018) Notch Signaling Activation Enhances Human Adipose-Derived Stem Cell Retinal Differentiation. Stem Cells International 2018. Artn 9201374 https://doi.org/10.1155/2018/ 9201374

159. Amirpour, N., Amirizade, S., Hashemibeni, B., Kazemi, M., Hadian, M., \& Salehi, H. (2019). Differentiation of eye field neuroectoderm from human adipose-derived stem cells by using 
small-molecules and hADSC-conditioned medium. Annals of Anatomy-Anatomischer Anzeiger, 221, 17-26. https://doi.org/10. 1016/j.aanat.2018.08.002.

160. Salehi, H., Razavi, S., Esfandiari, E., Kazemi, M., Amini, S., \& Amirpour, N. (2019). Application of Hanging Drop Culture for Retinal Precursor-Like Cells Differentiation of Human AdiposeDerived Stem Cells Using Small Molecules. Journal of Molecular Neuroscience, 69(4), 597-607. https://doi.org/10.1007/s12031019-01388-8

161. Zhang, Y., Zhang, D. D., Wei, W., Shen, B. Q., Wang, Y. Y., Zhang, Y. J., Zhang, Y. D., Ji, J., Sun, H., Luo, M., \& Gu, P. (2017). Effects of RPE-conditioned medium on the differentiation of hADSCs into RPE cells, and their proliferation and migration. Experimental and Therapeutic Medicine, 14(4), 3699-3707. https://doi.org/10.3892/etm.2017.4997.

162. Rezanejad, H., Soheili, Z. S., Haddad, F., Matin, M. M., Samiei, S., Manafi, A., \& Ahmadieh, H. (2014). In vitro differentiation of adipose-tissue-derived mesenchymal stem cells into neural retinal cells through expression of human PAX6 (5a) gene. Cell and Tissue Research, 356, 65-75. https://doi.org/10.1007/s00441014-1795-y.

163. Roozafzoon, R., Lashay, A., Vasei, M., Ai, J., Khoshzaban, A., Keshel, S. H., Barabadi, Z., \& Bahrami, H. (2015). Dental pulp stem cells differentiation into retinal ganglion-like cells in a three dimensional network. Biochemical and Biophysical Research Communications. https://doi.org/10.1016/j.bbrc.2014.12.069.

164. Bray, A. F., Cevallos, R. R., Gazarian, K., \& Lamas, M. (2014). Human dental pulp stem cells respond to cues from the rat retina and differentiate to express the retinal neuronal marker rhodopsin. Neuroscience. https://doi.org/10.1016/j.neuroscience.2014.09. 023.

165. Choi SW, Shin JH, Kim JJ, Shin TH, Seo Y, Kim HS, Kang KS (2016) Direct cell fate conversion of human somatic stem cells into cone and rod photoreceptor-like cells by inhibition of microRNA-203. Oncotarget. https://oi.org/10.18632/oncotarget. 9882

166. Choi, S. W., Kim, J. J., Seo, M. S., Park, S. B., Shin, T. H., Shin, J. H., Seo, Y., Kim, H. S., \& Kang, K. S. (2017). Inhibition by miR410 facilitates direct retinal pigment epithelium differentiation of umbilical cord blood-derived mesenchymal stem cells. Journal of Veterinary Science, 18(1), 59-65. https://doi.org/10.4142/jvs. 2017.18.1.59

167. Lejkowska, R., Kawa, M. P., Pius-Sadowska, E., Roginska, D., Luczkowska, K., Machalinski, B., \& Machalinska, A. (2019). Preclinical Evaluation of Long-Term Neuroprotective Effects of BDNF-Engineered Mesenchymal Stromal Cells as Intravitreal Therapy for Chronic Retinal Degeneration in Rd6 Mutant Mice. International Journal of Molecular Sciences, 20(3), ARTN 777. https://doi.org/10.3390/ijms20030777.

168. Machalińska, A., Kawa, M., Pius-Sadowska, E., Stępniewski, J., Nowak, W., Rogińska, D., Kaczyńska, K., Baumert, B., Wiszniewska, B., Józkowicz, A., Dulak, J., \& Machaliński, B. (2013). Long-term neuroprotective effects of NT-4-engineered mesenchymal stem cells injected intravitreally in a mouse model of acute retinal injury. Invest Ophth Vis Sci. https://doi.org/10. 1167/iovs.13-12221.

169. Guan, Y., Cui, L., Qu, Z., Lu, L., Wang, F., Wu, Y., Zhang, J., Gao, F., Tian, H., Xu, L., Xu, G., Li, W., Jin, Y., \& Xu, G. (2013). Subretinal Transplantation of Rat MSCs and Erythropoietin Gene Modified Rat MSCs for Protecting and Rescuing Degenerative Retina in Rats. Current Molecular Medicine. https://doi.org/10. 2174/15665240113139990071.

170. Shirley Ding, S. L., Leow, S. N., Munisvaradass, R., Koh, E. H., Bastion, M. L. C., Then, K. Y., Kumar, S., \& Mok, P. L. (2016). Revisiting the role of erythropoietin for treatment of ocular disorders. Eye (Basingstoke), 30, 1293-1309. https://doi.org/10. 1038/eye.2016.94.

171. Ding SLS, Kumar S, Khan MSA, Mok PL (2018) Human Mesenchymal Stem Cells Expressing Erythropoietin Enhance Survivability of Retinal Neurons Against Oxidative Stress: An In Vitro Study. Frontiers in Cellular Neuroscience 12. ARTN 190 https://doi.org/10.3389/fncel.2018.00190

172. Kim, J. Y., Park, S., Park, S. H., Lee, D., Kim, G. H., Noh, J. E., Lee, K. J., \& Kim, G. J. (2020). Overexpression of pigment epithelium-derived factor in placenta-derived mesenchymal stem cells promotes mitochondrial biogenesis in retinal cells. Laboratory Investigation. https://doi.org/10.1038/s41374-0200470-Z.

173. Lee, J. Y., Shin, J. M., Yeum, C. E., Chae, G. T., Chun, M. H., \& Oh, S. J. (2012). Intravitreal delivery of mesenchymal stem cells loaded onto hydrogel affects the regulatory expression of endogenous NGF and BDNF in ischemic rat retina. Tissue Engineering and Regenerative Medicine. https://oi.org/10.1007/s13770-0120355-3.

174. Manchineella, S., Thrivikraman, G., Basu, B., \& Govindaraju, T. (2016). Surface-functionalized silk fibroin films as a platform to guide neuron-like differentiation of human mesenchymal stem cells. ACS Applied Materials and Interfaces. https://doi.org/10. 1021/acsami.6b06403.

175. Soleimannejad, M., Ebrahimi-Barough, S., Soleimani, M., Nadri, S., Tavangar, S. M., Roohipoor, R., Yazdankhah, M., Bayat, N., Riazi-Esfahani, M., \& Ai, J. (2018). Fibrin gel as a scaffold for photoreceptor cells differentiation from conjunctiva mesenchymal stem cells in retina tissue engineering. Artificial Cells, Nanomedicine and Biotechnology. https://doi.org/10.1080/ 21691401.2017.1345922.

176. Weiss JN, Levy S, Benes SC (2015) Stem cell ophthalmology treatment study (SCOTS) for retinal and optic nerve diseases: A case report of improvement in relapsing auto-immune optic neuropathy. Neural Regeneration Research. https://doi.org/10.4103/ 1673-5374.165525

177. Weiss, J. N., Levy, S., \& Malkin, A. (2015). Stem cell ophthalmology treatment study (SCOTS) for retinal and optic nerve diseases: A preliminary report. Neural Regeneration Research. https://doi.org/10.4103/1673-5374.158365.

178. Weiss, J. N., \& Levy, S. (2018). Stem Cell Ophthalmology Treatment Study: bone marrow derived stem cells in the treatment of Retinitis Pigmentosa. Stem Cell Investig, 5, 18. https://doi.org/ 10.21037/sci.2018.04.02

179. Satarian L, Nourinia R, Safi S, Kanavi MR, Jarughi N, Daftarian N, Arab L, Aghdami N, Ahmadieh H, Baharvand H (2017) Intravitreal injection of bone marrow mesenchymal stem cells in patients with advanced retinitis pigmentosa; A safety study. Journal of Ophthalmic and Vision Research. https://oi.org/10. 4103/2008-322X.200164

180. Gu, X., Yu, X., Zhao, C., Duan, P., Zhao, T., Liu, Y., Li, S., Yang, Z., Li, Y., Qian, C., Yin, Z., \& Wang, Y. (2018). Efficacy and Safety of Autologous Bone Marrow Mesenchymal Stem Cell Transplantation in Patients with Diabetic Retinopathy. Cellular Physiology and Biochemistry. https://doi.org/10.1159/ 000492838 .

181. Limoli, P. G., Vingolo, E. M., Morales, M. U., Nebbioso, M., \& Limoli, C. (2014). Preliminary study on electrophysiological changes after cellular autograft in age-related macular degeneration. Medicine (Baltimore), 93(29), e355. https://doi.org/10.1097/ MD.0000000000000355.

182. Limoli PG, Limoli C, Vingolo EM, Scalinci SZ, Nebbioso M (2016) Cell surgery and growth factors in dry age-related macular degeneration: Visual prognosis and morphological study. Oncotarget. https://doi.org/10.18632/oncotarget.10442 
183. Oner, A., Gonen, Z. B., Sinim, N., Cetin, M., \& Ozkul, Y. (2016). Subretinal adipose tissue-derived mesenchymal stem cell implantation in advanced stage retinitis pigmentosa: a phase I clinical safety study. Stem Cell Research and Therapy. https://doi.org/ 10.1186/s13287-016-0432-y.

184. Oner, A., Gonen, Z. B., Sevim, D. G., Smim Kahraman, N., \& Unlu, M. (2018). Suprachoroidal adipose tissue-derived mesenchymal stem cell implantation in patients with dry-type age-related macular degeneration and stargardt's macular dystrophy: 6-month follow-up results of a phase 2 study. Cellular Reprogramming. https://doi.org/10.1089/cell.2018.0045.

185. Özmert, E., \& Arslan, U. (2020). Management of retinitis pigmentosa by Wharton's jelly derived mesenchymal stem cells: Preliminary clinical results. Stem Cell Research and Therapy. https://doi.org/10.1186/s13287-020-1549-6.

186. Mangunsong, C., Putera, B., Haifa, R., Suwandjaja, M., Sharina, A., Sasongko, M. B., \& Wirohadidjojo, Y. W. (2019). Safety Issues of Peribulbar Injection of Umbilical Cord Mesenchymal Stem Cell (Uc-Msc) in Patients with Retinitis Pigmentosa. Cytotherapy, 21(5), S83-S83. https://doi.org/10.1016/j.jcyt.2019. 03.500 .

187. Ding, S. S. L., Subbiah, S. K., Khan, M. S. A., Farhana, A., \& Mok, P. L. (2019). Empowering mesenchymal stem cells for ocular degenerative disorders. International Journal of Molecular Sciences. https://doi.org/10.3390/ijms20071784.

188. Lee, S., Choi, E., Cha, M. J., \& Hwang, K. C. (2015). Cell adhesion and long-term survival of transplanted mesenchymal stem cells: A prerequisite for cell therapy. Oxidative Medicine and Cellular Longevity. https://doi.org/10.1155/2015/632902.

189. Inoue, Y., Iriyama, A., Ueno, S., Takahashi, H., Kondo, M., Tamaki, Y., Araie, M., \& Yanagi, Y. (2007). Subretinal transplantation of bone marrow mesenchymal stem cells delays retinal degeneration in the RCS rat model of retinal degeneration. Exp Eye Res, 85, 234-241. https://doi.org/10.1016/j.exer.2007.04.007.

190. Johnson, T. V., Bull, N. D., \& Martin, K. R. (2009). Transplantation prospects for the inner retina. Eye. https://doi. org/10.1038/eye.2008.376.

191. Lohan, P., Treacy, O., Morcos, M., Donohoe, E., O'donoghue, Y., Ryan, A. E., Elliman, S. J., Ritter, T., \& Griffin, M. D. (2018). Interspecies Incompatibilities Limit the Immunomodulatory Effect of Human Mesenchymal Stromal Cells in the Rat. Stem Cells. https://doi.org/10.1002/stem.2840.

192. Johnson, T. V., Bull, N. D., \& Martin, K. R. (2010). Identification of barriers to retinal engraftment of transplanted stem cells. Investigative Ophthalmology and Visual Science. https://oi.org/ 10.1167/iovs.09-3884.

193. Tassoni, A., Gutteridge, A., Barber, A. C., Osborne, A., \& Martin, K. R. (2015). Molecular Mechanisms Mediating Retinal Reactive Gliosis Following Bone Marrow Mesenchymal Stem Cell Transplantation. Stem Cells. https://doi.org/10.1002/stem.2095.
194. Çerman, E., Akkoç, T., Eraslan, M., Şahin, Ö., Özkara, S., Aker, F. V., Subași, C., Karaöz, E., \& Akkoç, T. (2016). Retinal electrophysiological effects of intravitreal bone marrow derived mesenchymal stem cells in streptozotocin induced diabetic Rats. PLoS ONE, 11, 1-23. https://doi.org/10.1371/journal.pone.0156495.

195. Marfy-Smith, S. J., \& Clarkin, C. E. (2017). Are Mesenchymal Stem Cells So Bloody Great After All? Stem cells translational medicine, 6, 3-6. https://doi.org/10.5966/sctm.2016-0026.

196. Caplan, A. I., \& Dennis, J. E. (2006). Mesenchymal stem cells as trophic mediators. Journal of Cellular Biochemistry. https://doi. org $110.1002 / j \mathrm{jcb} .20886$.

197. Kinnaird, T., Stabile, E., Burnett, M. S., Lee, C. W., Barr, S., Fuchs, S., \& Epstein, S. E. (2005). Marrow-derived stromal cells express genes encoding a broad spectrum of arteriogenic cytokines and promote in-vitro and in-vivo arteriogenesis through paracrine mechanisms (vol 94, pg 678, 2004). Circulation Research, 97(3), E51-E51.

198. Campbell, M., \& Doyle, S. L. (2019). Current perspectives on established and novel therapies for pathological neovascularization in retinal disease. Biochemical Pharmacology. https://doi.org/ 10.1016/j.bcp.2019.04.029.

199. Kremer H, Gebauer J, Elvers-Hornung S, Uhlig S, Hammes HP, Beltramo E, Steeb L, Harmsen MC, Sticht C, Klueter H, Bieback K, Fiori A (2020) Pro-angiogenic Activity Discriminates Human Adipose-Derived Stromal Cells From Retinal Pericytes: Considerations for Cell-Based Therapy of Diabetic Retinopathy. Frontiers in Cell and Developmental Biology 8. ARTN 387 https://doi.org/10.3389/fcell.2020.00387

200. Tso, G. H. W., Law, H. K. W., Tu, W. W., Chan, G. C. F., \& Lau, Y. L. (2010). Phagocytosis of Apoptotic Cells Modulates Mesenchymal Stem Cells Osteogenic Differentiation to Enhance IL-17 and RANKL Expression on CD4+T Cells. Stem Cells, 28(5), 939-954.

201. Mazzoni, F., Safa, H., \& Finnemann, S. C. (2014). Understanding photoreceptor outer segment phagocytosis: Use and utility of RPE cells in culture. Exp Eye Res, 126, 51-60.

202. Park, S. S., Bauer, G., Abedi, M., Pontow, S., Panorgias, A., Jonnal, R., Zawadzki, R. J., Werner, J. S., \& Nolta, J. (2015). Intravitreal autologous bone marrow cd34+ cell therapy for ischemic and degenerative retinal disorders: Preliminary phase 1 clinical trial findings. Investigative Ophthalmology and Visual Science. https://doi.org/10.1167/iovs.14-15415.

203. Kuriyan, A. E., Albini, T. A., Townsend, J. H., Rodriguez, M., Pandya, H. K., Leonard, R. E., Parrott, M. B., Rosenfeld, P. J., Flynn, H. W., \& Goldberg, J. L. (2017). Vision loss after intravitreal injection of autologous "stem Cells" for AMD. New England Journal of Medicine. https://doi.org/10.1056/NEJMoa1609583.

Publisher's Note Springer Nature remains neutral with regard to jurisdictional claims in published maps and institutional affiliations. 